\title{
Autofluorescence of atmospheric bioaerosols: spectral fingerprints and taxonomic trends of pollen
}

\author{
C. Pöhlker ${ }^{1}$, J. A. Huffman ${ }^{1,2}$, J.-D. Förster ${ }^{1}$, and U. Pöschl ${ }^{1}$ \\ ${ }^{1}$ Max Planck Institute for Chemistry, Biogeochemistry Department and Multiphase Chemistry Department, P.O. Box 3060, \\ 55020 Mainz, Germany \\ ${ }^{2}$ University of Denver, Department of Chemistry and Biochemistry, 2190 E. Illif Ave., Denver, Colorado 80208, USA \\ Correspondence to: C. Pöhlker (c.pohlker@mpic.de) and J. A. Huffman (alex.huffman@du.edu)
}

Received: 11 May 2013 - Published in Atmos. Meas. Tech. Discuss.: 24 June 2013

Revised: 9 October 2013 - Accepted: 12 October 2013 - Published: 9 December 2013

\begin{abstract}
Primary biological aerosol particles (PBAP) are important factors in atmospheric cycling, climate, and public health. Pollen is a major fraction of PBAP and is receiving increasing attention due to its high allergenic potential and the associated impacts on personal life quality and economy. Recently, autofluorescence-based techniques have proven to be valuable tools for real time, in situ quantification and classification of PBAP. First studies suggest that the autofluorescence of pollen may be sufficiently selective to be utilized for an automated and real-time monitoring of pollen in ambient air. However, the degree of selectivity autofluorescence can provide is still in question and actively debated.

This study addresses the origin, properties, and selectivity of autofluorescence from natural pollen by fluorescence microscopy and spectroscopy measurements along with a systematic synthesis of related literature. We show that dry pollen reveals characteristic and reproducible autofluorescence signatures which are shaped by cell wall associated fluorophores, such as phenolic compounds and carotenoid pigments. In addition, fluorescence signals from proteins and chlorophyll $a$ were observed in some species. The abundance and intensity of the individual fluorescence signals show certain taxonomic trends and allow systematic differentiation from bacteria and fungal spores due to the lack of proteins on the grain surface. Principal component analysis was used to explore the discrimination potential of pollen autofluorescence, in combination with size and shape, revealing a differentiation of pollen on family level. Our results help explore the levels of selectivity that autofluorescence-based techniques can provide to PBAP analysis and will support the
\end{abstract}

development and application of autofluorescence-based detectors for monitoring of allergenic pollen in the atmosphere.

\section{Introduction}

\subsection{Primary biological aerosol particles and atmospheric relevance}

Primary biological aerosol particles (PBAP) ${ }^{1}$, also called bioaerosols, consist of a complex mixture of small biogenic particles, which are directly released from the biosphere into the atmosphere (Després et al., 2012). The major constituents of PBAP are microorganisms (e.g., bacteria and algae), reproductive units (e.g., pollen, fungal spores, bacterial spores and viruses), as well as fragments and excretions of various organisms (e.g., plant debris and bacterial vesicles) spanning a wide size range from a few nanometers to hundreds of micrometers (e.g., Kuehn and Kesty, 2005; Elbert et al., 2007; Burrows et al., 2009). Bioaerosols are globally ubiquitous and can dominate the coarse aerosol burden in certain ecosystems (e.g., Pöschl et al., 2010). PBAP have received increased attention in atmospheric science due to their impact on atmospheric chemistry and physics (Pöschl, 2005; Möhler et al., 2007; Deguillaume et al., 2008), their important role in biogeochemical (Gorbushina and Broughton, 2009; Mahowald et al., 2011) and hydrological cycling (Morris et al., 2008; Huffman et al., 2013; Prenni et al., 2013; Tobo et al., 2013), as well as their influence on public and agricultural health (D'Amato, 2000; Bernstein et al., 2004).

\footnotetext{
${ }^{1} \mathrm{~A}$ list of frequently used acronyms can be found in Appendix A.
} 
Pollen is the male gametophyte in the life cycle of sexually reproducing plants and thus plays a crucial role in plant reproduction and ecology (Nepi and Franchi, 2000; Taiz and Zeiger, 2010). Pollen development in the plant stamen, its maturation and release as well as pollen-stigma recognition and pollen tube growth represent a highly specialized developmental process (e.g., Bedinger et al., 1994; Pacini, 2000; Boavida et al., 2005). Plants rely on either abiotic (i.e., wind-driven, called anemophilous) or biotic (i.e., insect mediated, called entomophilous) pollination methods (Sofiev et al., 2009). Pollen that are dispersed anemophilously are "optimized" for atmospheric transport (i.e., small physical and aerodynamic grain size, low density, e.g., due to air bladders, lacking sticky coating) and account for $\sim 10 \%$ of all pollen species. Anemophilous pollen (range 10-100 $\mu \mathrm{m}$, average $20-30 \mu \mathrm{m}$ ) marks the upper size limit of airborne biological material with typical number concentrations around $\sim 10 \mathrm{~m}^{-3}$ in ambient air (Wilson et al., 1973; Sofiev et al., 2006, 2009). Though generally less abundant in number than other classes of atmospheric bioaerosols, such as fungal spores at $\sim 10^{3}-10^{4} \mathrm{~m}^{-3}$ (Fröhlich-Nowoisky et al., 2009) or bacteria at $\sim 10^{4}-10^{5} \mathrm{~m}^{-3}$ (Burrows et al., 2009), pollen concentrations can increase to $10^{3} \mathrm{~m}^{-3}$ during strong pollination events (Siljamo et al., 2008). The number concentration of small PBAP could be underestimated in some cases due to the fact that pollen can swell and burst after taking up water, releasing $10^{2}-10^{3}$ particles (Taylor et al., 2007). Despite their relatively large physical diameter and high sedimentation velocities, intact pollen grains frequently undergo long distance dispersal (up to $\sim 10^{3} \mathrm{~km}$ ) (e.g., Kel$\operatorname{logg}$ and Griffin, 2006; Sofiev et al., 2006; Kuparinen et al., 2009), and thus may impact the biology of the destination and atmospheric properties en route. Thus, potential changes in pollination patterns due to climate change are discussed as a major uncertainty regarding biodiversity and ecosystem stability (Tylianakis et al., 2008; Zhang et al., 2013).

During the last few decades, pollen have received increasing attention due to their strong allergenicity and severe impacts on human health (e.g., Franze et al., 2005; Reid and Gamble, 2009; Sofiev et al., 2009). Between 10 and $25 \%$ of the European population are affected by seasonal allergenic rhinitis, causing substantial impact to personal life quality and to national economies as a result of lost work time (Traidl-Hoffmann et al., 2003; Scharring et al., 2006; Diethart et al., 2007). Therefore, substantial technical, financial and scientific efforts have been invested in developing reliable aeroallergen monitoring and forecasting systems (e.g., Kalman et al., 1997; Ranzato et al., 2007; Scheifinger et al., 2013). However, quantification and identification of pollen is a demanding task due to highly diverse and variable pollen concentrations in the atmosphere, as well as influence of environmental conditions (e.g., relative humidity) and air pollutants (e.g., ozone and nitrogen oxides) (e.g., Franze et al., 2005; Shiraiwa et al., 2012). In particular, the role of small and respirable allergenic entities - so called daughter aller- gens or paucimicronic particles - which are released from the pollen surface and/or from the cytosol upon pollen grain bursting is poorly understood (e.g., D'Amato, 2000; Taylor et al., 2007; Wang et al., 2012). Furthermore, observations suggest that the atmospheric abundances of pollen grains and allergenic submicron particles, after pollen burst, are frequently decoupled in time, thus complicating efforts to develop a coherent allergen monitoring strategy. This suggests that a combination of direct-counting and immunodetection techniques may be necessary to adequately predict airborne allergen levels (Razmovski et al., 2000).

In addition to health related effects, pollen may impact atmospheric cycling and cloud microphysics (Möhler et al., 2007; Prenni et al., 2009; Hoose and Möhler, 2012). Pope (2010) showed that pollen can act as efficient cloud condensation nuclei $(\mathrm{CCN})$; however, their low atmospheric number concentration prevents them from being important on a global scale. In contrast, many studies have reported the high ice nucleation activity (INA) of various pollen species and highlight their potential importance for mixedphase clouds in biologically-influenced environments (Dingle, 1966; Diehl et al., 2001, 2002; von Blohn et al., 2005; Pummer et al., 2012). Although pollen grains are assumed to account only for a small fraction of INA on a global scale, their local and regional impact on cloud microphysics could be substantial (Hoose et al., 2010), especially when considering the large increase in pollen fragment number as a result of grain rupture.

\subsection{Autofluorescence in bioaerosol detection}

The term autofluorescence, or intrinsic fluorescence, denotes fluorescent light emission from a material based on the presence of fluorophores, for example cell constituents such as proteins and coenzymes (Pöhlker et al., 2012; Andrade-Eiroa et al., 2013). The term is to be distinguished from extrinsic fluorescence achieved through the use of fluorescent stains applied to otherwise nonfluorescent material, such as biological cells allowed to interact with fluorescent dyes (e.g., Hawe et al., 2008). Among a large variety of techniques for the investigation of atmospheric PBAP, autofluorescencebased instruments have received increasing attention in the last few decades (e.g., Ho, 2002; Kaye et al., 2005; Hill et al., 2009; Sivaprakasam et al., 2009; Bundke et al., 2010). Such instruments utilize the emission of laser/light induced fluorescence (LIF) from biological material, providing a quantitative, nondestructive, and in situ detection of atmospheric biological particles in real time. Thus, LIF instruments overcome certain drawbacks in traditional PBAP analysis, such as high labor cost, low time resolution and lack of quantitative information (Burrows et al., 2009).

The application of LIF to bioaerosol detection relies on the basic assumption that the intrinsic fluorescence within the measured spectral range of biological material exceeds that of potentially interfering nonbiological matter. This may be 
a valid assumption in many cases, suggesting that LIF techniques can, to a large degree, identify many types of biological aerosol particles on top of a complex and variable mixture of other atmospheric aerosol types. However, the exact relationship between the fraction of detected fluorescent biological aerosol particles (FBAP) and the fraction of all PBAP remains unclear and is surely dependent on specific instrument parameters and the sampled aerosol types. One reason is that the fluorescence properties of biological and nonbiological materials are not separated by a clear offset, but rather show overlapping properties (Hill et al., 2009; Huffman et al., 2012). Biological particles exhibiting weak fluorescence will not be counted by LIF instrumentation (Huffman et al., 2012; Pöhlker et al., 2012). As a further complication, small particles are prone to escape LIF detection because fluorescence intensity, as a function of fluorophore abundance in the cell, depends strongly on particles size (e.g., Sivaprakasam et al., 2004; Healy et al., 2012b). Thus, it has been suggested that FBAP number is, in many cases, a lower limit of PBAP number (Huffman et al., 2010), but further work is needed to explore and quantify this relationship. It is also expected, for example, that certain nonbiological aerosols could show elevated fluorescence (e.g., polycyclic aromatic hydrocarbons, PAH and some secondary organic aerosol, SOA) and would thus represent false-positive counts (Bones et al., 2010; Lee et al., 2013). The concentration of PAH is expected to be low at particle sizes $>1 \mu \mathrm{m}$ and would not contribute significantly to fluorescent particle number. Huffman et al. (2012) also showed that during a measurement campaign in the Amazon, diurnal SOA patterns were clearly distinct from those of FBAP and that influence from SOA to fluorescence aerosol was thus likely to be minimal. In contrast, however, Gabey et al. (2013) suggest that, for a remote French mountain site, nonbiological aerosol, including possible SOA, may explain an important fraction of fluorescence aerosol signal. Certain types of mineral dust and humic-like substances (HULIS) could also be detected as fluorescent, and this will undoubtedly confound FBAP interpretation. Comparing FBAP size distributions from a commercially available bioaerosol LIF instrument with contemporaneous filter samples analyzed via microscopy, Huffman et al. (2012) concluded that the LIF instrument was reliably able to provide lower-limit values of PBAP in a pristine rainforest location, but that more work was necessary to apply the same conclusions more broadly.

In the context of ambient bioaerosol detection, three major fields of LIF application can be distinguished: (i) the detection of biological warfare agents (BWA), (ii) the analysis of PBAP in atmospheric science, and (iii) the selective online monitoring of aeroallergens. (i) The development of LIF instruments for BWA detection has mainly been conducted by military research facilities. Their aim is to develop early warning systems for BWA threats, which requires a quick, reliable recognition of potentially harmful organisms (e.g., Jeys et al., 2007). (ii) Commercialization of LIF instruments has triggered their application in the atmospheric sci- ence community for field-based PBAP analysis. Here, LIF is utilized to explore the concentration, composition, temporal and spatial variability as well as characteristic size and emission patterns of PBAP in different environments. A growing number of studies has been published which provide new and important insights into the PBAP cycling in the ambient atmosphere (e.g., Gabey et al., 2010; Huffman et al., 2010, 2012; Pöschl et al., 2010; Gabey, 2011; Toprak and Schnaiter, 2013). Currently, applications in atmospheric science are designed primarily to quantify the total PBAP burden rather than to differentiate individual classes or species. (iii) The development of a reliable monitoring infrastructure for major aeroallergens, such as pollen and molds, is a concern of high medical and societal interest (e.g., Scharring et al., 2006). LIF techniques feature real-time detection capability and certain taxonomical selectivity. Therefore promising efforts have begun to utilize LIF techniques for pollen monitoring (Ronneberger et al., 2002; Mitsumoto et al., 2009, 2010).

The quality of the discrimination ability between biological and nonbiological aerosol particles is strongly dependent on the spectral design of the LIF bioaerosol detector (i.e., excitation wavelengths and emission detection bands). Thus, the application of LIF for bioaerosol quantification and classification requires a sound knowledge of the fluorescence properties of the target bioaerosol particles. Accordingly, a number of studies have been conducted in the laboratory to characterize the LIF detection process and to understand it on a molecular level. One strategy utilizes well-defined, laboratory-generated standard bioaerosols to analyze the corresponding response of online LIF instruments (Agranovski et al., 2003; Kanaani et al., 2008; Healy et al., 2012a). Such experiments provide important information about the sensitivity and selectivity of instruments and their optical configurations. Another strategy uses offline techniques to measure and characterize the general autofluorescence signature of selected bioaerosol types. In some studies fluorescence microscopy is used to understand general fluorescence patterns and fluorophore locations in bioaerosol proxies (e.g., Roshchina et al., 2004; Herbrich et al., 2012). Other studies have applied fluorescence spectroscopy to understand characteristic emission signatures (e.g., O'Connor et al., 2011). Particularly, excitation-emission matrices (EEMs) can be a useful tool for a systematic characterization of steady-state autofluorescence signatures (Satterwhite, 1990; Wlodarski et al., 2006; Hill et al., 2009; Mularczyk-Oliwa et al., 2012; Andrade-Eiroa et al., 2013; Saari et al., 2013). They can be used as "roadmaps" to identify spectral regions with high fluorescence levels, good signal-to-noise ratios and high degrees of selectivity (Pan et al., 2007).

\subsection{Scope and aim of this study}

This paper follows our recent study on bioaerosol autofluorescence and therefore the studies can be regarded as Part 1 (Pöhlker et al., 2012) and Part 2 (this study). Part 1 
provides a detailed introduction into the field of autofluorescence for PBAP detection and analysis. It addresses the question of whether the complex autofluorescence signals from bioaerosols can be traced back to individual biofluorophores on a molecular level. Therefore, Part 1 provides a systematic summary of literature knowledge on (bio)fluorophores and a fluorescence spectroscopic characterization of the most important fluorophores in PBAP and nonbiological interferences. Part 1 operates on the simple level of pure, individual biofluorophores and uses EEMs as an appropriate offline tool. Metrics, such as spectral properties, intensity and fluorophore abundance in PBAP, are utilized to explore bioaerosols autofluorescence on a molecular basis.

This Part 2 study operates with the concepts introduced in Part 1 and is motivated by the same scientific questions. However, here we extend the analytical scope from pure fluorescent molecules to whole biological particles, thus adding a layer of complexity. As outlined in the introduction, atmospheric PBAP is a very diverse mixture of suspended biological material. Ultimately, it is an open question of what type of information autofluorescence techniques may provide in atmospheric PBAP analysis. The present study aims to help to reduce the uncertainty associated with LIF applications in PBAP analysis by means of a systematic analysis of standard biological particles. Here, we focus on pollen as an adequate bioaerosol type. We suggest that this systematic investigation (i) gives a clear and general picture on the autofluorescence properties of dry pollen and (ii) illustrates, by means of one standard particle type, how offline fluorescence techniques can support the application of LIF in ambient air.

The use of pollen as a model PBAP type is motivated here by two main reasons. First, from an experimental point of view, we found that pollen represent ideal test particles because of their strong and diverse fluorescence signatures. Moreover, the large grain size supports microscopic analysis and allows the resolution of cellular details and autofluorescent "fine structure". Therefore, within this first explorative study, pollen is appropriate to illustrate the scope and limits of the techniques. The second reason is that pollen represents atmospheric particles of high relevance, particularly due to its high allergenic potential with severe social and economic impacts. Therefore, a reliable, selective, and automated pollen monitoring infrastructure which can be operated in real time is highly desirable, but technically not yet practicable. Autofluorescence-based techniques have proven to be highly valuable tools for the analysis of atmospheric bioaerosols. Thus, autofluorescence is regarded as a promising candidate for a selective in situ monitoring of allergenic pollen in the air. Here, we aim to contribute to this discussion by systematically exploring the autofluorescence properties of pollen and to assess their applicability for ambient measurements.

\section{Materials and methods}

\subsection{Chemicals and materials}

Most pollen samples were purchased from commercial vendors: Allergon AB (Ängelholm, Sweden), Sigma Aldrich (St. Louis, MO, USA), Thermo Scientific (Waltham, MA, USA) and Polyscience (Niles, IL, USA) (see Table 1 for detailed information). On inquiry, the providers assured that their marketed standard pollen samples can be regarded as natural, which means that no chemical (e.g., dewaxing) or comparably harsh treatment was applied after harvest and that the pollen were stored under cool and dry conditions ${ }^{2}$. The purity of the purchased pollen samples was carefully checked by microscopy. In addition to standard pollen from commercial providers, various further samples were collected freshly in a local park in Mainz, Germany, during spring pollination season; three of these samples are included in this study for comparison (see Table 1). Fresh pollen samples were collected by shaking plant flowers over a clean glass surface. In the course of the manuscript, the term natural pollen is used for both freshly harvested and commercially obtained samples, which were collected without any post-processing except sieving. All other chemicals were purchased from Sigma Aldrich and Merck (Darmstadt, Germany) and used as delivered.

The consistency of the pollen fluorescence properties across different sources was carefully evaluated. Two pollen species (B. papyrifera and A. artemisiifolia) were each obtained from two different providers, and EEMs were shown to be identical, irrespective of commercial source (Fig. S1). The metabolic status of pollen is a potentially important aspect in the analysis of pollen autofluorescence properties. It is usually described by means of pollen viability (via staining protocols with specific fluorescent dyes) and/or germinability (via in vitro tube growth experiments) (Sato et al., 1998; Ferri et al. 2008). Both viability and germinability decay with time as a function of storage length, temperature, and relative humidity (Van Der Walt and Littlejohn, 1996). An experimental assessment of pollen viability and germinability is rather complex, and therefore, a systematic examination of pollen metabolic state and quantitative comparison with autofluorescence properties is beyond the scope of the current study. However, we performed a number of simple experiments and comparisons, which indicate that freshly collected and aged pollen samples show overall similar autofluorescence properties: (i) in general, fresh and purchased pollen showed similar appearance as measured by fluorescence microscopy analysis (compare Fig. 2). (ii) Relatively fresh and aged pollen samples of $P$. alba (collected in March

\footnotetext{
${ }^{2}$ The only exception is $A$. stolonifera. In this case, dewaxing with acetone was conducted after harvesting. No substantial differences in morphology and fluorescence to the untreated pollen samples were observed. A. stolonifera included in the analysis is treated carefully.
} 
Table 1. Overview of pollen species analyzed in this study. Pollen grain diameters are obtained from: (a) microscopy measurements in this study (Sect. 2.2), (b) product information from pollen vendor Allergon AB, or (c) database: http://www.polleninfo.org (23 February 2013) $(\mathrm{SD}=$ standard deviation). Axis aspect ratios were measured for pollen in dry state (Sect. 2.2). The last two columns indicate if fluorescence microscopy (FM) and fluorescence spectroscopy (FS) data for certain species are shown in this manuscript.

\begin{tabular}{|c|c|c|c|c|c|c|c|c|c|}
\hline \multirow{2}{*}{ \# } & \multicolumn{2}{|c|}{ Name } & \multirow[t]{2}{*}{ Family } & \multirow{2}{*}{$\begin{array}{l}\text { Pollination } \\
\text { method }\end{array}$} & \multirow{2}{*}{$\begin{array}{l}\text { Source/ } \\
\text { Provider }\end{array}$} & \multirow{2}{*}{$\begin{array}{c}\text { Size }(\mu \mathrm{m}) \\
\text { Mean } \pm \text { SD }\end{array}$} & \multirow{2}{*}{$\begin{array}{r}\text { Aspect ratio } \\
\text { major/minor } \\
\text { axes }\end{array}$} & \multicolumn{2}{|c|}{ Analysis } \\
\hline & Latin & Common & & & & & & FM & FS \\
\hline 1 & Agrostis stolonifera & Creeping bentgrass & Poaceae & anemophilous & Allergon $\mathrm{AB}$ & $23 \pm 3^{(a)} 23 \pm 1^{(b)}$ & $25 / 21$ & no & yes \\
\hline 2 & Alnus glutinosa & Black alder & Betulaceae & anemophilous & Allergon $\mathrm{AB}$ & $26 \pm 2^{\text {(a) }} 24 \pm 2^{\text {(b) }}$ & $27 / 25$ & no & yes \\
\hline 3 & Alnus incana & Grey/speckled alder & Betulaceae & anemophilous & Allergon AB & $25 \pm 4^{(\mathrm{a})} 24 \pm 1^{\text {(b) }}$ & $26 / 23$ & no & yes \\
\hline 4 & Amaranthus retroflexus & Common amaranth & Amaranthaceae & anemophilous & Allergon $\mathrm{AB}$ & $25 \pm 4^{(\mathrm{a})} 28 \pm 1^{(\mathrm{b})}$ & $27 / 24$ & no & yes \\
\hline 5 & Ambrosia artemisiifolia & Common ragweed & Asteraceae & anemophilous & $\begin{array}{l}\text { Polyscience, } \\
\text { Allergon } \mathrm{AB}\end{array}$ & $21 \pm 1^{(\mathrm{a})} 21 \pm 1^{(\mathrm{b})}$ & $21 / 20$ & yes & yes \\
\hline 6 & Artemisia tridentata & Giant sage/sagebrush & Asteraceae & anemophilous & Sigma Aldrich & $21 \pm 3^{\text {(a) }}$ & $25 / 18$ & yes & yes \\
\hline 7 & Artemisia vulgaris & Common mugwort & Asteraceae & anemophilous & Allergon AB & $18 \pm 2^{\text {(a) }} 19 \pm 1^{\text {(b) }}$ & $20 / 17$ & yes & yes \\
\hline 8 & Betula fontinalis & Waterbirch & Betulaceae & anemophilous & Sigma Aldrich & $27 \pm 3^{(\mathrm{a})}$ & $30 / 26$ & yes & yes \\
\hline 9 & Betula pendula & White birch & Betulaceae & anemophilous & Allergon $\mathrm{AB}$ & $24 \pm 3^{(\mathrm{a})} 24 \pm 1^{\text {(b) }}$ & $26 / 23$ & no & yes \\
\hline 10 & Brassica napus & Rape & Brassicaceae & entomophilous & Allergon $\mathrm{AB}$ & $30 \pm 7^{\text {(a) }} 28 \pm 1^{\text {(b) }}$ & $39 / 22$ & no & yes \\
\hline 11 & Broussonetia papyrifera & Paper mulberry & Moraceae & anemophilous & $\begin{array}{l}\text { Thermo scientific, } \\
\text { Polyscience }\end{array}$ & $12 \pm 2^{(a)}$ & $14 / 11$ & yes & yes \\
\hline 12 & Carpinus betulus & Hornbeam & Betulaceae & anemophilous & Allergon $\mathrm{AB}$ & $37 \pm 5^{\text {(a) }} 35 \pm 2^{\text {(b) }}$ & $41 / 33$ & yes & yes \\
\hline 13 & Corylus avellana & Common hazel & Betulaceae & anemophilous & Allergon $\mathrm{AB}$ & $26 \pm 4^{(\mathrm{a})} 23 \pm 1^{(\mathrm{b})}$ & $28 / 23$ & no & yes \\
\hline 14 & Cynodon dactylon & Bermuda grass & Poaceae & anemophilous & Sigma Aldrich & $25 \pm 3^{(\mathrm{a})}$ & $28 / 24$ & no & yes \\
\hline 15 & $\begin{array}{l}\text { Fagus sylvatica } \\
\text { (2009 and 2013) }\end{array}$ & European beech & Fagaceae & anemophilous & Allergon AB & $\begin{array}{l}\text { 2009: } 45 \pm 4^{(\mathrm{a})} \\
2013: 43 \pm 3^{(\mathrm{a})}\end{array}$ & $\begin{array}{l}\text { 2009: } 49 / 40 \\
\text { 2013: } 45 / 40\end{array}$ & yes & yes \\
\hline 16 & Juglans californica & California walnut & Juglandaceae & anemophilous & Allergon AB & $34 \pm 5^{\text {(a) }} 39 \pm 3^{\text {(b) }}$ & $37 / 31$ & no & yes \\
\hline 17 & Juglans nigra & Black walnut & Juglandaceae & anemophilous & Sigma Aldrich & $37 \pm 4^{(\mathrm{a})}$ & $41 / 34$ & no & yes \\
\hline 18 & Lolium perenne & Perennial ryegrass & Poaceae & anemophilous & Allergon $\mathrm{AB}$ & $42 \pm 9^{(a)} 40 \pm 3^{(b)}$ & $47 / 37$ & yes & yes \\
\hline 19 & Matricaria chamomilla & Chamomile & Asteraceae & entomophilous & Fresh collection & - & - & yes & no \\
\hline 20 & Olea europaea & European olive & Oleaceae & anemophilous & Allergon $\mathrm{AB}$ & $21 \pm 2^{\text {(a) }} 23 \pm 1^{(b)}$ & $24 / 19$ & no & yes \\
\hline 21 & Phleum pratense & Timothy grass & Poaceae & anemophilous & Allergon $\mathrm{AB}$ & $34 \pm 4^{(\mathrm{a})} 35 \pm 2^{\text {(b) }}$ & $36 / 31$ & ves & yes \\
\hline 22 & Pinus sylvestris & Scotch pine & Pinaceae & anemophilous & Allergon $\mathrm{AB}$ & $42 \pm 5^{(\mathrm{a})} 51 \pm 4^{(\mathrm{b})}$ & $45 / 39$ & yes & yes \\
\hline 23 & Poa pratensis & Kentucky bluegrass & Poaceae & anemophilous & Allergon $\mathrm{AB}$ & $28 \pm 3^{(a)} 29 \pm 2^{(b)}$ & $31 / 25$ & no & yes \\
\hline 24 & $\begin{array}{l}\text { Populus alba } \\
\text { (2011 and 2013) }\end{array}$ & Silver poplar & Salicaceae & anemophilous & Allergon $\mathrm{AB}$ & $\begin{array}{l}\text { 2011: } 26 \pm 3^{(a)} \\
\text { 2013: } 24 \pm 3^{(a)}\end{array}$ & $\begin{array}{r}\text { 2011: } 28 / 23 \\
2013: 26 / 22\end{array}$ & yes & yes \\
\hline 25 & Populus nigra italica & Lombardy poplar & Salicaceae & anemophilous & Sigma Aldrich & $25 \pm 2^{(a)}$ & $27 / 24$ & no & yes \\
\hline 26 & Populus tremuloides & Aspen & Salicaceae & anemophilous & Sigma Aldrich & $26 \pm 3^{(\mathrm{a})}$ & $29 / 24$ & yes & yes \\
\hline 27 & Quercus robur & English oak & Fagaceae & anemophilous & Allergon AB & $31 \pm 3^{\text {(a) }} 30 \pm 1^{\text {(b) }}$ & $38 / 23$ & yes & yes \\
\hline 28 & Rumex acetosa & Common sorrel & Polygonaceae & anemophilous & Allergon $\mathrm{AB}$ & $20 \pm 2^{\text {(a) }} 19 \pm 2^{\text {(b) }}$ & $21 / 18$ & no & yes \\
\hline 29 & Sambucus nigra & Elder & Adoxaceae & entomophilous & Fresh collection & $17 \pm 2^{\text {(a) }} 18 \pm 1^{\text {(c) }}$ & $19 / 16$ & no & yes \\
\hline 30 & Secale cereale & Cultivated rye & Poaceae & anemophilous & Sigma Aldrich & $48 \pm 4^{(\mathrm{a})}$ & $56 / 39$ & yes & yes \\
\hline 31 & Symphoricarpos albus & Common snowberry & Caprifoliaceae & entomophilous & Fresh collection & - & - & yes & no \\
\hline
\end{tabular}

2013 vs. March 2011) and F. sylvatica (collected in May 2013 vs. April 2009) were analyzed by fluorescence microscopy and spectroscopy. Figure S2 reveals no clear qualitative differences in fluorescence microstructure between the younger and older pollen. However, an increase in fluorescence intensity of all grains was observed in aged samples. Figure S3 shows that the spectral fingerprint in the corresponding EEMs of younger vs. older pollen is nearly identical; however, it also confirms the trend of increasing fluorescence intensity with aging. (iii) The EEM of very fresh (1 day after collection) S. nigra pollen (Fig. S4q) resembles the general fluorescence signatures of commercial (aged) pollen samples. Based on these crosschecks we assume in the following that the fluorescence properties of commercially obtained and freshly harvested pollen samples are overall similar, except for increasing intensity with age, and that all samples are generally comparable.

\subsection{Fluorescence microscopy}

Fluorescence microscopy images were taken on a BZ9000 Fluorescence Microscope (Keyence, Inc., Osaka, Japan). The instrument was equipped with a superhigh-compression mercury lamp $(120 \mathrm{~W})$ and a $2 / 3$ inch, 1.5 mega pixel monochrome CCD. The following fluorescence filters were used to take images in different spectral ranges: OP-66834 DAPI-BP $\left(\lambda_{\text {ex }}=360 / 20 \mathrm{~nm}\right.$, $\left.\lambda_{\text {Dichroic }}=400 \mathrm{~nm}, \lambda_{\text {Absorp }}=460 / 25 \mathrm{~nm}\right)$, OP-66836 GFP-BP $\left(\lambda_{\text {ex }}=470 / 20 \mathrm{~nm}, \lambda_{\text {Dichroic }}=495 \mathrm{~nm}, \lambda_{\text {Absorp }}=535 / 25 \mathrm{~nm}\right)$, OP-66838 TexasRed $\left(\lambda_{\mathrm{ex}}=560 / 20 \mathrm{~nm}, \lambda_{\text {Dichroic }}=595 \mathrm{~nm}\right.$, $\left.\lambda_{\text {Absorp }}=630 / 30 \mathrm{~nm}\right)$. Filter specifications are represented as mode wavelength and peak width $(\lambda / F W H M ; F W H M=$ full width half max). The spectral characteristics of the microscope filters are illustrated in Fig. 1. 
For microscopy analysis the pollen samples were placed between a specimen holder and a cover slide and fixed with one of the two following mounting media: (i) glycerol gelatin (Sigma Aldrich), which is an aqueous mounting medium; or (ii) Eukitt ${ }^{\circledR}$ (Sigma Aldrich), which is a polymethacrylatebased and quickly hardening medium. A small amount of pollen was placed on the specimen holder and one drop of the mounting medium was added. Glycerin gelatin was diluted with $\sim 40 \%$ (vol) of water and heated to $\sim 60^{\circ} \mathrm{C}$ to decrease its viscosity for easy handling. Pollen and mounting medium were carefully homogenized with a spatula and a cover slide was placed on top of the mixture. After $\sim 20 \mathrm{~min}$ of hardening the samples were used for microscopy analysis. The aqueous medium of the glycerol gelatin allows the investigation of pollen grains in a moist state. This is due to the fact that dry pollen mounted in contact with glycerol gelatin quickly take up water and will thus swell within a matter of minutes before analysis (Reitsma, 1969; Praglowski, 1970). In contrast, the Eukitt ${ }^{\circledR}$ medium preserves the $d r y$ state of the pollen grains. Preparation in moist state was applied for most samples, whereas dry state preparation was chosen occasionally, as outlined in Sect. 3.1. Glycerol gelatin also introduces weak background fluorescence in all three channels (mostly in blue), whereas no background was observed for Eukitt ${ }^{\circledR}$.

The microscopy investigation was initiated immediately $(<30 \mathrm{~min})$ after sample preparation and pollen grains were exposed to the excitation radiation for as little time as possible ( $\sim$ seconds) to minimize photo-bleaching effects. The exposure time in all channels was adjusted to a maximum dynamic range by increasing the signal to just below the detector saturation threshold. Raw images were processed with software: BW Analyzer (Keyence, Inc.) and Adobe Photoshop (Adobe Systems Inc., San Jose, CA, USA). Fluorescence overlay images were prepared by merging individual images from three fluorescence channels. Histogram equalization was performed for all channels by manually adjusting the dynamic range between the pixel of maximum brightness and the background, which was set to black zero level. This procedure corrects for photo-bleaching related intensity decrease. For low background fluorescence levels, this does not change the image's color balance.

Pollen grain sizes and axis aspect ratios in Table 1 were obtained as follows. Under the bright field microscope, a certain number of separated pollen grains in dry state (50150 grains) were imaged and sizing was performed with the software BW Analyzer. The given diameters are the arithmetic mean values for all imaged grains, averaged over grain dimensions in $x$ and $y$ direction. Aspect ratios correspond to the measured major and minor axes of the pollen. Note that the orientation of individual grains on the specimen slide is not uniform and that the given aspect ratios are therefore approximate.

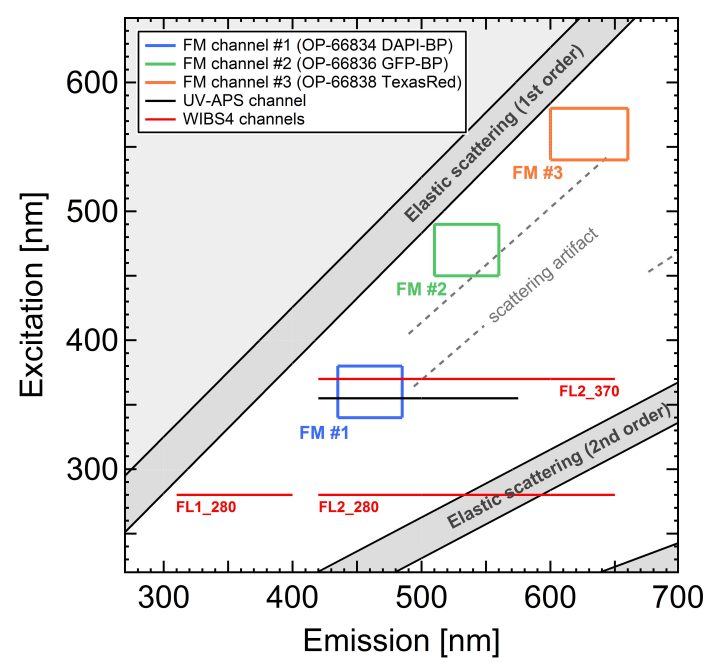

Fig. 1. Conceptual excitation-emission matrix (EEM) showing (1) fluorescence data area (white), areas strongly influenced by elastic (i.e., Rayleigh) light scattering (grey diagonal bars), and area without meaningful data (upper left triangle). Dashed lines indicate weak elastic light scattering, probably due to an instrumental artifact that occurred for all dry samples investigated in this study. (2) Operational range of commercially available bioaerosols detectors UV-APS and WIBS-4 (Hairston et al., 1997; Foot et al., 2008; Robinson et al., 2013). Length of individual lines indicates measured emission band for a certain excitation wavelength shown as sharp line. Instrument specifications: UV-APS (single wavelength laser excitation, $\lambda_{\mathrm{ex}}=355 \mathrm{~nm}, \lambda_{\mathrm{em}}=420-575 \mathrm{~nm}$ ); WIBS-4 (dualwavelength Xe-lamp excitation, $\lambda_{\mathrm{ex}, 1}=280, \lambda_{\mathrm{em}, 280}=310-400$, $420-650 ; \lambda_{\mathrm{ex}, 2}=370, \lambda_{\mathrm{em}, 370}=420-650$ ). (3) Spectral range of three fluorescence microscope (FM) channels used in this study. Spectral specifications of filters: DAPI-BP $\left(\lambda_{\mathrm{ex}}=360 / 20 \mathrm{~nm}\right.$, $\left.\lambda_{\text {Dichroic }}=400 \mathrm{~nm}, \lambda_{\text {Absorp }}=460 / 25 \mathrm{~nm}\right) ; \operatorname{GFP}-\mathrm{BP}\left(\lambda_{\mathrm{ex}}=470 / 20\right.$, $\left.\lambda_{\text {Dichroic }}=495, \quad \lambda_{\text {Absorp }}=535 / 25\right) ; \quad$ TexasRed $\quad\left(\lambda_{\text {ex }}=560 / 20\right.$, $\left.\lambda_{\text {Dichroic }}=595, \lambda_{\text {Absorp }}=630 / 30\right)$. For comparisons and further information refer to (Pöhlker et al., 2012; Andrade-Eiroa et al., 2013).

\subsection{Fluorescence spectroscopy}

Fluorescence spectra were recorded on a LS 45 Luminescence Spectrometer (Perkin Elmer, Inc., Waltham, MA, USA) and a detailed instrument description is given in our Part 1 paper (Pöhlker et al., 2012). EEMs are measured in a spectral area of $220-650 / 270-700 \mathrm{~nm}\left(\Delta \lambda_{\text {ex }} / \Delta \lambda_{\text {em }}\right)$, which covers most biofluorophores relevant to atmospheric PBAP and the detection ranges of most LIF bioaerosols detectors (Pöhlker et al., 2012). Figure 1 displays a conceptual overview-EEM illustrating the spectral zones of interest, elastic scattering interferences, and instrumental parameters. The dry pollen samples were analyzed with a Front Surface Accessory (Perkin Elmer, Inc.). Several milligrams of powder were placed onto the sample holder, each in a thin, homogeneous layer. In subsequent EEM runs of the same pollen sample, no strong variations in the EEM appearance (i.e., 
intensity, spectral pattern) were observed. The obtained spectra can be regarded as a stable and reproducible result. The resulting EEMs were processed and normalized as described in Part 1.

\subsection{Principal component analysis}

Principal component analysis (PCA) was used as a statistical tool to visualize taxonomic trends in pollen autofluorescence. PCA was performed using Origin 8.6 (OriginLab Corp., Northampton, MA, USA) based on fluorescence spectroscopy data from 29 pollen species (Table 1). The following pollen features were used as PCA input data: (i) intensities of the main fluorescence modes A $\left(\lambda_{\mathrm{ex}}=280 /\right.$ $\left.\Delta \lambda_{\mathrm{em}}=440-460\right)$, B $(355 / 440-460)$, and C (460/510-530). These mode intensities are normalized to total fluorescence intensity, which results in a better scattering of data points in the PCA plot, compared to the non-normalized input data. The other three features used as PCA input data were (ii) total fluorescence intensity, as average of fluorescence from modes A-C; (iii) pollen grain size (Table 1); and (iv) pollen grain shape, as aspect ratio of major vs. minor axes (Table 1).

\section{Results and discussion}

Pollen grains exhibit strong emission of autofluorescent light originating from both their cytosol (intra-cell components) and their complex, multilayered cell wall (e.g., Asbeck, 1955; Driessen et al., 1989; Castro et al., 2010). The natural fluorescence of pollen has been used as a valuable tool for quick and noninvasive in situ analyses of fresh and fossil pollen in diverse scientific fields, such as atmospheric science (e.g., Ronneberger et al., 2002; Mitsumoto et al., 2010; Pan et al., 2011), geology and palynology (e.g., Phillips, 1972; Yeloff and Hunt, 2005), as well as plant physiology and botany (e.g., Roshchina, 2003, 2008, 2012; Grienenberger et al., 2009). The following sections characterize the autofluorescence of native pollen using fluorescence microscopy and spectroscopy.

\subsection{Fluorescence microscopy}

Common white light (or bright field) microscopy is an important and wide-spread technique for pollen characterization and counting (i.e., for routine pollen monitoring), and therefore a large body of pollen-related microscopy data ${ }^{3}$ is available. Fluorescence microscopy, in contrast, has been applied only occasionally for the characterization of pollen. In addition to size and shape, it provides information about surface texture and internal structures as well as spectral proper-

\footnotetext{
${ }^{3}$ http://www.polleninfo.org

http://pollen.usda.gov/Light_Micrographs/LMicro.html http://oldweb.geog.berkeley.edu/ProjectsResources/PollenKey/ pollen.htm

http://www.geo.arizona.edu/palynology/nsw/index.html
}

ties (e.g., Asbeck, 1955; Driessen et al., 1989; Ronneberger et al., 2002; Roshchina et al., 2004; Scharring et al., 2006; Mitsumoto et al., 2009; Castro et al., 2010). Morphologically, it allows localization of cellular origin and estimation of relative contributions of fluorescence emission from different cellular regions (i.e., cell wall, organelles, cytosol). It also provides spectroscopic information about the predominant excitation and emission ranges and allows a pollen classification based on specific emission intensity ratios (Mitsumoto et al., 2009, 2010; Castro et al., 2010). Analyses utilizing microspectroscopic approaches even allow the analysis of fluorescence spectra for single pollen grains (e.g., Roshchina et al., 2004).

Previous studies have reported that the complex and multilayered pollen cell wall (sporoderm) is the main source of pollen autofluorescence (e.g., Driessen et al., 1989; Roshchina et al., 1997; Grienenberger et al., 2009; Castro et al., 2010). The sporoderm is a unique feature of pollen and generally consists of two components: exine and intine. The intine forms the internal part of the sporoderm; it comprises cellulose and related compounds and it is chemically similar to the primary cell wall of plants (Bedinger et al., 1994). The exine is a chemically and morphologically unique biopolymer and comprises the outermost layer of the sporoderm showing a species-specific sculptured morphology (Brooks and Shaw, 1978; Scott, 1994). It consists of the exceptionally resistant biopolymer sporopollenin whose complex chemical composition is not fully characterized. Its biosynthesis is assumed to be based on a mixture of phenolic, fatty acid and probably carotenoid precursors (Bedinger et al., 1994). Moreover, the exine is usually coated with an oily substance called pollenkitt (up to $10-15 \%$ of total pollen mass), containing a mixture of lipids as well as carotenoid, flavonoid, and phenolic pigments (Wiermann and Vieth, 1983; Pacini and Hesse, 2005). The complexity of the pollen's sporoderm reflects the plurality of its functions, such as protection against harsh environmental conditions (Boavida et al., 2005), pollen-stigma interaction and recognition (Piffanelli et al., 1998), and regulation of the pollen's hydration state (Dickinson, 1995). One major function is UV-light shielding to avoid radiative damage to the DNA and physiological processes in the cell (Rozema et al., 2001; Jacobs et al., 2007). The UV-light reduction occurs via light reflection, absorption as well as fluorescence light conversion from UV to the visible spectral range and is mainly based on sporoderm pigments (Hoque and Remus, 1999).

Figures 2 and 3 show selected fluorescence microscopy images of pollen grains from different species. Figure 2 exhibits overview images of 12 selected pollen samples, providing a visual impression of their diverse autofluorescence appearance. Figure 3 focusses on individual grains from 6 species and shows cytological details with the highest resolution accessible for full-field light microscopy. Our aim in this fluorescence microscopy section is to highlight intracellular autofluorescent structures. We found that pollen in 

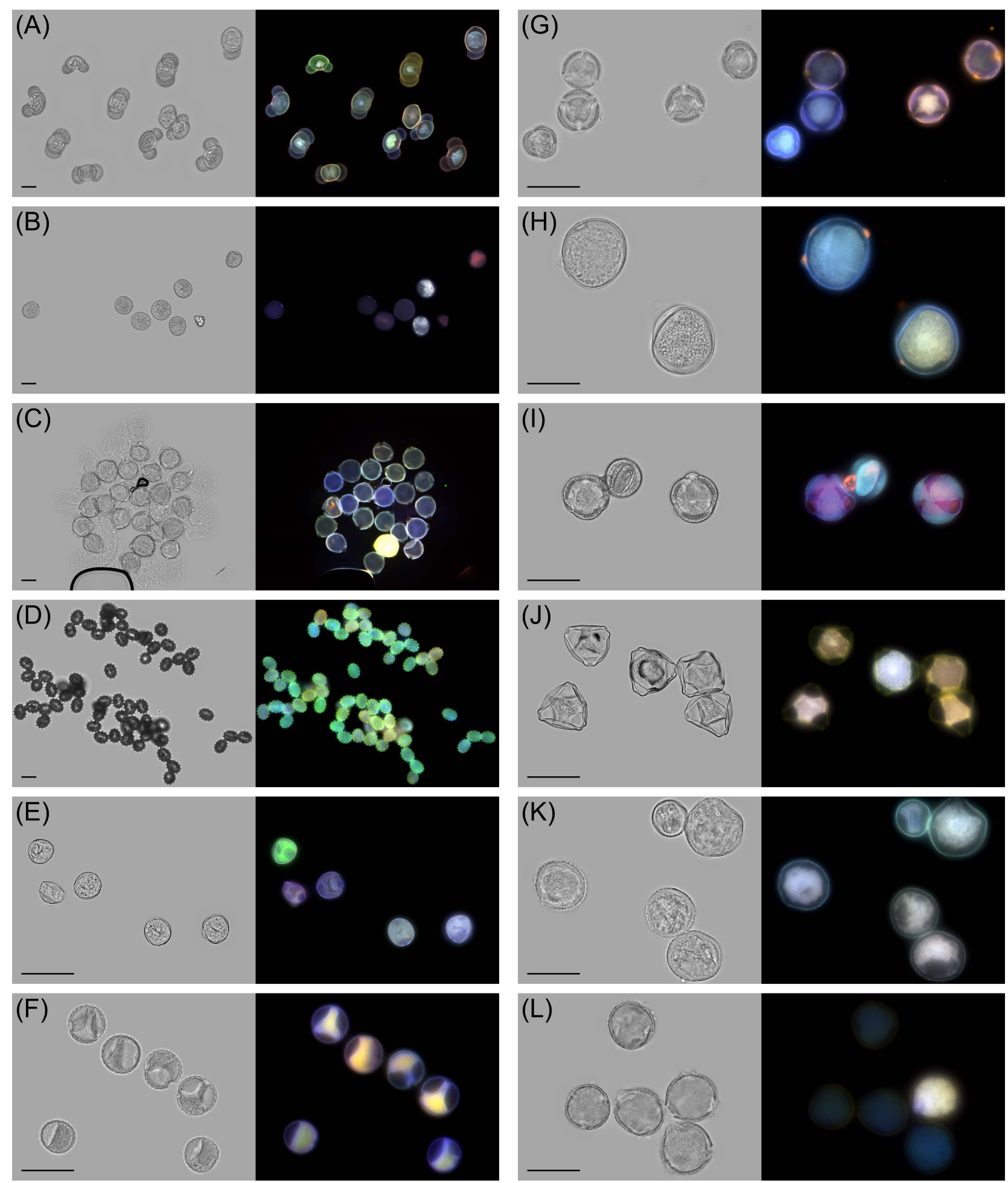

Fig. 2. Overview panel with fluorescence microscopy (FM) images from 12 selected pollen species, shown in bright field (left) and fluorescence mode (right). Fluorescence mode images are displayed as overlay based on three fluorescence channels. Most pollen samples are prepared in moist state, a few samples in dry state (see Sect. 2.2). Individual images show (A) Pinus sylvestris in moist state; (B) Phleum pratense, moist; (C) Symphoricarpos albus, moist, pollen grains are burst due to osmotic pressure; (D) Matricaria chamomilla, dry; (E) Broussonetia papyrifera, moist; (F) Ambrosia artemisiifolia, dry; (G) Artemisia vulgaris, moist; (H) Lolium perenne, moist; (I) Artemisia tridentata, moist; (J) Betula fontinalis, in immersion oil; (K) Populus tremuloides, moist; (L) Quercus robur, moist. All images with focal plane through center of grains - only exception is A. tridentata with focal plane through upper part of cell wall. Scale bar $=30 \mu \mathrm{m}$ in all images. 
moist state are most appropriate for microscopy analysis because cellular components are thus most visible, and the majority of pollen samples were prepared accordingly (see Sect. 2.2). In a few cases, dry sample preparation was preferred to highlight specific morphological aspects. We are aware that water uptake changes the pollen's morphology due to grain swelling (Diehl et al., 2001; Castro et al., 2010; Griffiths et al., 2012). This water effect has important atmospheric implications, but a detailed discussion is beyond the scope of this study.

In the course of our microscopy analysis, we made four main observations, which are listed here as (i) to (iv) and discussed separately and in detail in the following four paragraphs. (i) Grains from all pollen species show fluorescent emission with cell wall and cytosolic contributions (e.g., Fig. $2 g$ and h). (ii) The relative emission intensities of individual pollen grains of the same species can vary significantly, with fluorescence from few individual grains being much higher than of the majority (e.g., Fig. 2c and 1; also Fig. 3e). (iii) Differences in emission wavelengths among pollen grains of the same species are common and qualitatively observable as different colors in the fluorescence overlay images (e.g., Fig. 2e and g; also Fig. 3e). (iv) In several cases, the fluorescence overlay images provide better contrast and "perceptibility" of the pollen microarchitecture (i.e., patterns in the cell wall and internal cytosolic structures) than the corresponding bright field images (e.g., Fig. $2 \mathrm{i}$ and Fig. 3a and c).

i. Our results confirm that the pollen sporoderm contributes substantially to the overall fluorescence emission. As typical examples, the high resolution images of $P$. sylvestris, $B$. fontinalis and A. artemisiifolia in Fig. 3a, c, and $\mathrm{f}$ exhibit a thick exine $(\sim 1-2 \mu \mathrm{m})$ which shows pronounced fluorescence. In these cases, the cell wall fluorescence occurred in the green-to-red range of the visible spectrum; however, the diversity of the cell wall appearance is high. In addition, many species show fluorescence contributions from other cell parts, such as the cytosol (e.g., Fig. $2 g$ and j; also Fig. $3 \mathrm{c}$ and d), specific organelles (e.g., Fig. 3a and f), and the air bladders in P. sylvestris (Fig. $3 \mathrm{a}$ and b). The blue, sometimes red tinted, cytosolic fluorescence is observed for many pollen species. In many cases the cytosol emission appears homogeneously distributed (Fig. 2h and k) and for other samples contrasts with the embedded nonfluorescent vesicular bodies (e.g., Fig. 3c), which are usually filled with oils (mostly in entomophilous pollen) or starch (mostly in anemophilous pollen) and serve as energy reserve for germination (Piffanelli et al., 1998).

ii. Previously, Castro et al. (2010) reported heterogeneous fluorescence intensity of individual pollen grains and stated that this variability is caused by different hydration states. In our study a heterogeneous intensity has been found for several species, in which some pollen grains show strongly increased cytosolic fluorescence compared with the majority of grains (i.e., Fig. $2 \mathrm{j}$ and 1 and Fig. 3e). Alternatively, differences in metabolic state can also explain this observation. Roshchina et al. $(1997,2003)$ reported a threefold increased intensity for pollen which have lost their viability $\left(\lambda_{\text {ex }}=360-380 \mathrm{~nm}\right)$. They further suggested utilizing this relationship as a quick and noninvasive in vivo diagnosis of the pollen cell state. The preliminary aging experiments in the current study support this idea because a trend of increasing fluorescence intensity with pollen age was found (compare Sect. 2.1, Figs. S2 and S3). Interestingly, a very similar effect has been observed for the fluorescence properties of fungal spores, which also show strongly increased emission intensities for nonviable compared to viable cells $\left(\lambda_{\mathrm{ex}}=\right.$ ultraviolet $)(\mathrm{Wu}$ and Warren, 1984a, b). In contrast, other studies report decaying fluorescence levels with increasing age of airborne fungal spores (e.g., Kanaani et al., 2007). Ultimately, more research is needed to understand the quantitative relationship between metabolic state and autofluorescence properties of biological material.

iii. In addition, the remarkable differences in emission wavelengths (visible as color differences) among grains of the same species may also be associated with differences in metabolic and maturation state, as reported by Roshchina et al. (2003). Some species show grains with very heterogeneous appearance (e.g., Fig. $2 \mathrm{e}$ and g), whereas others reveal more uniform properties (e.g., Fig. 2k). Phleum pratense in Fig. 3e represents a characteristic example with highly diverse fluorescence properties among grains which cannot be distinguished in the bright field image. It has been shown that during their development and maturation, the fluorescence properties of pollen undergo changes due to chemical and physiological transformations of the cell (Roshchina et al., 1997). Accordingly, the heterogeneity of pollen grains under the fluorescence microscope can be regarded as a visible reflection of such metabolic and maturational differences. This aspect is important for ambient PBAP detection, as highlighted by Pinnick et al. (2013), because single particle fluorescence may substantially differ from bulk fluorescence of the same material. Bulk fluorescence spectra, such as the EEMs presented in this study, provide an average characterization of fluorescent materials; however, differences on the level of individual cells are smeared. This introduces uncertainties and therefore complicates online pollen detection with LIF techniques because pollen fluorescence does not appear as a constant property across all grains. Instead, it reveals 

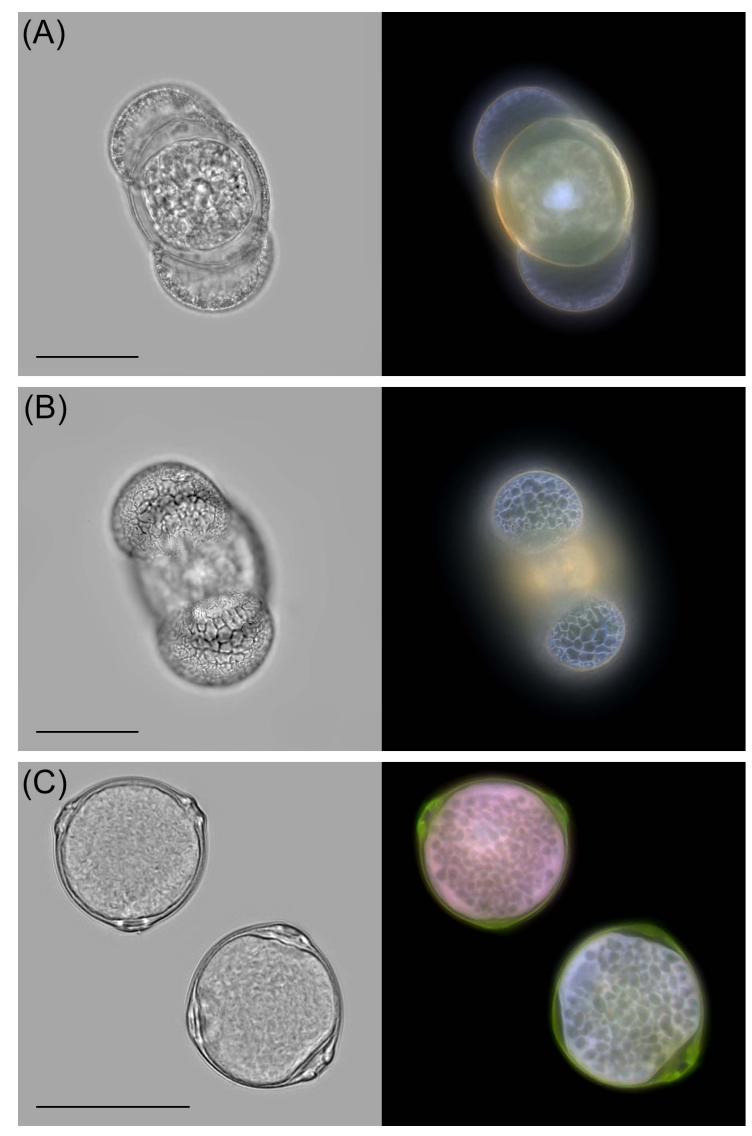
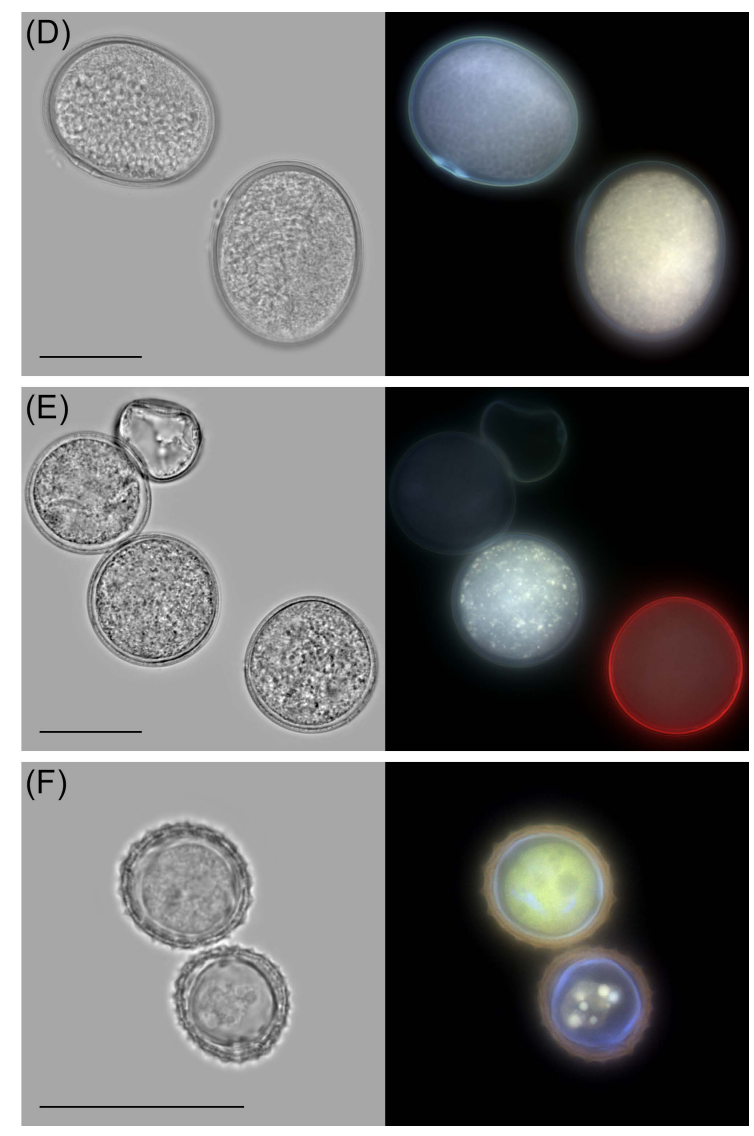

Fig. 3. High resolution microscopy images of selected pollen species in bright field (left) and fluorescence mode (right). Fluorescence images shown as overlay of three channels. (A) Pinus sylvestris, moist, with focal plane through center of grain. Image shows red fluorescence from cell wall and bluish cytosolic emission (i.e., from vegetative nucleus). (B) Pinus sylvestris, moist, with focal plane through air bladders highlighting blue fluorescence from skeleton-like structure inside air bladders with thin reddish cell wall around them. (C) Betula fontinalis, moist, showing green fluorescence from cell wall and apertures. Also blue-to-red cytosolic emission contrasting with nonfluorescent starch granules. (D) Secale cereale, moist, showing homogeneous cytosolic fluorescence and thin bluish cell wall. (E) Phleum pratense, moist, highlighting diverse fluorescence properties without obvious differences in bright field image. (F) Ambrosia artemisiifolia, moist, with blue fluorescing intine and red fluorescing exine. Also cytosol and strong organelle fluorescence. Scale bar $=30 \mu \mathrm{m}$ in all images.

a certain scattering around its average fluorescence parameters. This aspect is further discussed in Sect. 3.4.

iv. The images in Fig. 3 are recorded with the maximum resolution of a full-field fluorescence microscope. They show individual pollen grains in great detail and allow cytological and histological insights. The high contrast of the overlay fluorescence images reveals much more fine features of the pollen microarchitecture than the corresponding bright field images. In particular, the pollen's cytosol reveals a complex internal structure with membranes, vacuoles, organelles and nonfluorescent vesicular bodies. For example, the central spot of bluish-white fluorescence in the cytosol of $P$. sylvestris probably reveals the location of the (vegetative) nucleus (Fig. 3a). Moreover, in Fig. 3 b blue fluorescence shows a "foam-like" skeleton inside the air bladders of $P$. sylvestris and a thin red fluorescing membrane around them. In addition, details of the sporoderm are also resolved, such as an increased red fluorescence at the aperture in P. sylvestris (Fig. 3a) and a thickened cell wall at the apertures of $B$. fontinalis (Fig. 3c) with strong green fluorescence. Ambrosia artemisiifolia in Fig. 3f represents an interesting example of sporoderm fluorescence with a thick red tinted outer layer and a thin internal layer emitting bluish fluorescent light.

\subsection{Fluorescence spectroscopy}

The previous section discussed that fluorescence microscopy is a valuable technique to explore the morphological autofluorescence properties of individual pollen grains. The following section provides a spectral characterization of the steadystate autofluorescence properties of pollen and explains observed spectral signatures by assignment of individual 
Table 2. Summary of fluorescence modes in excitationemission matrices (EEMs) of dry and native pollen with spectral location and fluorophore assignment.

\begin{tabular}{lcl}
\hline $\begin{array}{l}\text { Fluorescence } \\
\text { mode }\end{array}$ & $\begin{array}{c}\text { Maximum }\left(\lambda_{\mathrm{ex}} / \lambda_{\mathrm{em}}\right) \\
(\mathrm{nm})\end{array}$ & Fluorophore \\
\hline A & $\sim 280 / 450$ & Phenolics \\
$\mathrm{B}$ & $\sim 360 / 450$ & Phenolics \\
$\mathrm{C}$ & $\sim 460 / 520$ & Carotenoids \\
D & $\sim 280 / 340$ & Protein \\
E & $\sim 350-650 / 675$ & Chlorophyll $a$ \\
\hline
\end{tabular}

fluorophores. EEMs were recorded for 29 different pollen species and Fig. 4 exhibits selected examples (for further EEMs see Supplement Fig. S4). Pollen show pronounced fluorescence within a wide spectral range with strongest excitation at $\lambda_{\mathrm{ex}}=220-550 \mathrm{~nm}$ and with corresponding emission at $\lambda_{\mathrm{em}}=380-600 \mathrm{~nm}$ (Fig. 4). The presence of multiple distinguishable, but overlapping, modes indicates fluorescent emission mixed from different fluorophores. The general fluorescence mode signature in the EEMs appears to be reproducible and characteristic across all analyzed pollen samples, as outlined below, suggesting a relatively few, but dominant, fluorophores common across most pollen species.

Among all dry pollen samples studied, three fluorescence modes appear most prominent: (A) a mode at $\sim 280 / 450 \mathrm{~nm}$ $\left(\lambda_{\text {ex }} / \lambda_{\text {em }}\right)$, (B) a mode at $\sim 355 / 450 \mathrm{~nm}$, and (C) a mode at $\sim 460 / 520 \mathrm{~nm}$. In addition to modes $\mathrm{A}-\mathrm{C}$, two further signals at $\sim 280 / 340 \mathrm{~nm}(\mathrm{D})$ and at $\sim 350-650 / 675 \mathrm{~nm}$ (E) were observed for a smaller number of samples. Table 2 provides a summary, including fluorophore assignment, which is discussed in detail in the following paragraphs. As a first, coarse classification, the 29 pollen samples can be subdivided into two groups: a first group with about 15 species, each showing a strong mode $C$ with rather weak or even undetectable modes A and B (e.g., B. fontinalis, Fig. 4d; J. nigra, Fig. 4g); and a second group with 14 species, each exhibiting clear, strong modes A, B, and C (e.g., A. vulgaris, Fig. 4c; L. perenne, Fig. 4h). In addition to the major signals, five samples show also mode $\mathrm{D}$, which appears for $C$. betulus (Fig. 4f) as a pronounced peak and for other species as a weak shoulder (e.g., P. pratense, Fig. 4i). Six samples show the very weak and multimodal signal E (e.g., A. vulgaris; Fig. 4c).

Based on all EEMs in Fig. 4 and Fig. S4, a general autofluorescence signature for native dry pollen was extracted and is shown in Fig. 5a. Here, the red markers represent the maxima of all clearly resolved modes in the individual pollen EEMs. The close clustering of the markers in the previously defined areas A-E indicates that the measured fluorescence is caused by a similar set of fluorescent compounds across the analyzed species. Moreover, a direct comparison with results from previous studies (Satterwhite, 1990; Wlodarski et al., 2006; Hill et al., 2009) underlines the characteristic clustering, particularly in the areas A-D (Fig. 5a). These results support the idea that dry pollen show consistent, fingerprintlike fluorescence signatures that can be used for fluorophore assignment (Pöhlker et al., 2012). Roshchina et al. (e.g., $1997,2003,2004)$ conducted a number of studies to analyze the autofluorescence of pollen and other secretory plant cells. Their experiments indicated that pollen fluorescence is dominated by sporoderm fluorophores and that phenolics $\left(\lambda_{\mathrm{em}}=440-490 \mathrm{~nm}\right)$, azulenes $\left(\lambda_{\mathrm{em}}=440-460 \mathrm{~nm}\right)$ and carotenoids $\left(\lambda_{\mathrm{em}}=500-560 \mathrm{~nm}\right)$ constitute the main classes.

In our experiments, emission at $\sim 450 \mathrm{~nm}$ (modes $\mathrm{A}$ and B; Fig. $5 \mathrm{c}$ and d) and $\sim 520 \mathrm{~nm}$ (mode C; Fig. $5 \mathrm{~b}$ and c) represent the most obvious and reproducible fluorescence features. Fluorophores usually show rather sharp and characteristic emission wavelengths, whereas excitation can occur over a comparably wide spectral range (Pöhlker et al., 2012). Thus, we assume that the modes A and B are caused by the same fluorophore type that is excited over a wide range, but most efficiently at 280 and $350 \mathrm{~nm}$ (Fig. 5f). The emission at $450 \mathrm{~nm}$ is consistent with phenolic fluorescence that is observed in most plant cell walls (e.g., Harris and Hartley, 1980; Lang et al., 1991; Hutzler et al., 1998). In addition, various studies, including real-time LIF ambient measurements, reported a similar and characteristic signal at $\sim 450 \mathrm{~nm}$ for pollen, confirming its ubiquitous role (Hill et al., 1999; Roshchina et al., 2004; Kiselev et al., 2011; O'Connor et al., 2011; Pan et al., 2011). Phenolic compounds represent the most abundant class of secondary plant metabolites in nature and typical subclasses in plant tissue and pollen are (i) hydroxylated cinnamic acid derivatives (e.g., ferulic, caffeic, $p$-coumaric and chlorogenic acid), (ii) flavonoid compounds (e.g., kaempferol and quercetin), and (iii) anthocyanins (e.g., cyanidin, malvidin) (Li et al., 2010; Taiz and Zeiger, 2010). The molecular skeleton of all these compounds comprises closely related conjugated structures of strongly oxygenfunctionalized phenolic moieties. The structural and electronic similarity across these phenolic subclasses explains similar excitation (i.e., UV range) and emission (i.e., blue spectral range) properties. Many cinnamic acids (i.e., ferulic and caffeic acid) are covalently bound to the cell walls (Lichtenthaler and Schweiger, 1998), whereas other phenolic fluorophores (e.g., trihydroxyferuloyl spermidine and many flavonoids in the pollen coat) are easily removed by washing (Wiermann and Vieth, 1983; Grienenberger et al., 2009). The large diversity of phenolic products in plants suggests that the pollen modes A and B are probably based on a mixture of fluorescent phenolic derivatives that exhibit similar emission at $450 \mathrm{~nm}$ and are "distributed" over a wide excitation range. However, Lichtenthaler and Schweiger (1998) suggest that among all fluorescent phenolics, ferulic acid plays a key role.

Mode $\mathrm{C}$ shows strong emission at $\sim 520 \mathrm{~nm}$, which is consistent with carotenoid fluorescence (Roshchina, 2003). Carotenoid pigments are widespread in nature, such as in 


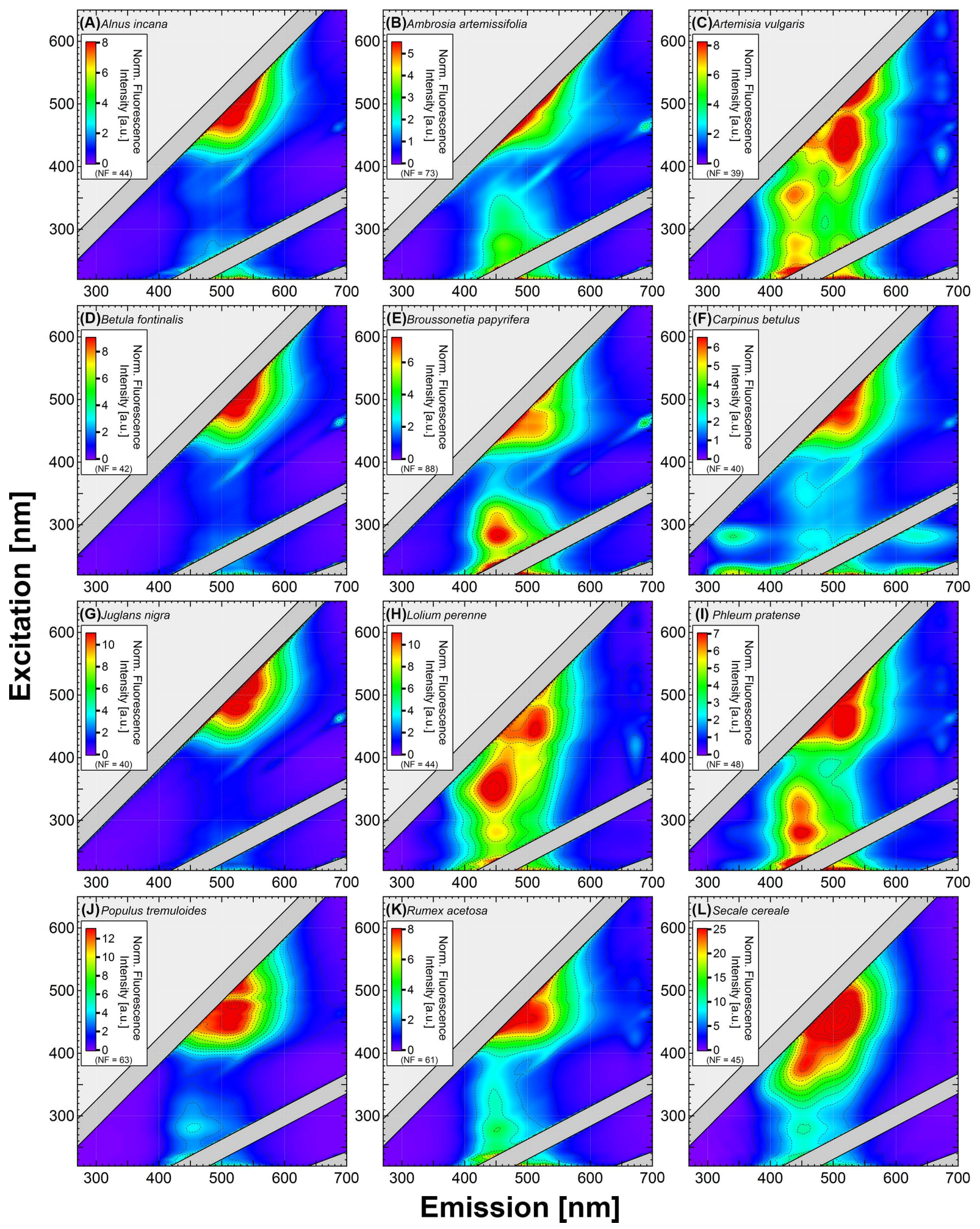

Fig. 4. Excitation-emission matrices (EEMs) of selected pollen species in dry state. Intensity color code has been adjusted to fluorescence intensity of individual samples. All EEMs are normalized as described in Pöhlker et al. (2012) and a normalization factor (NF) is reported in each panel. EEMs for further pollen species can be found in Supplement Fig. S4. 


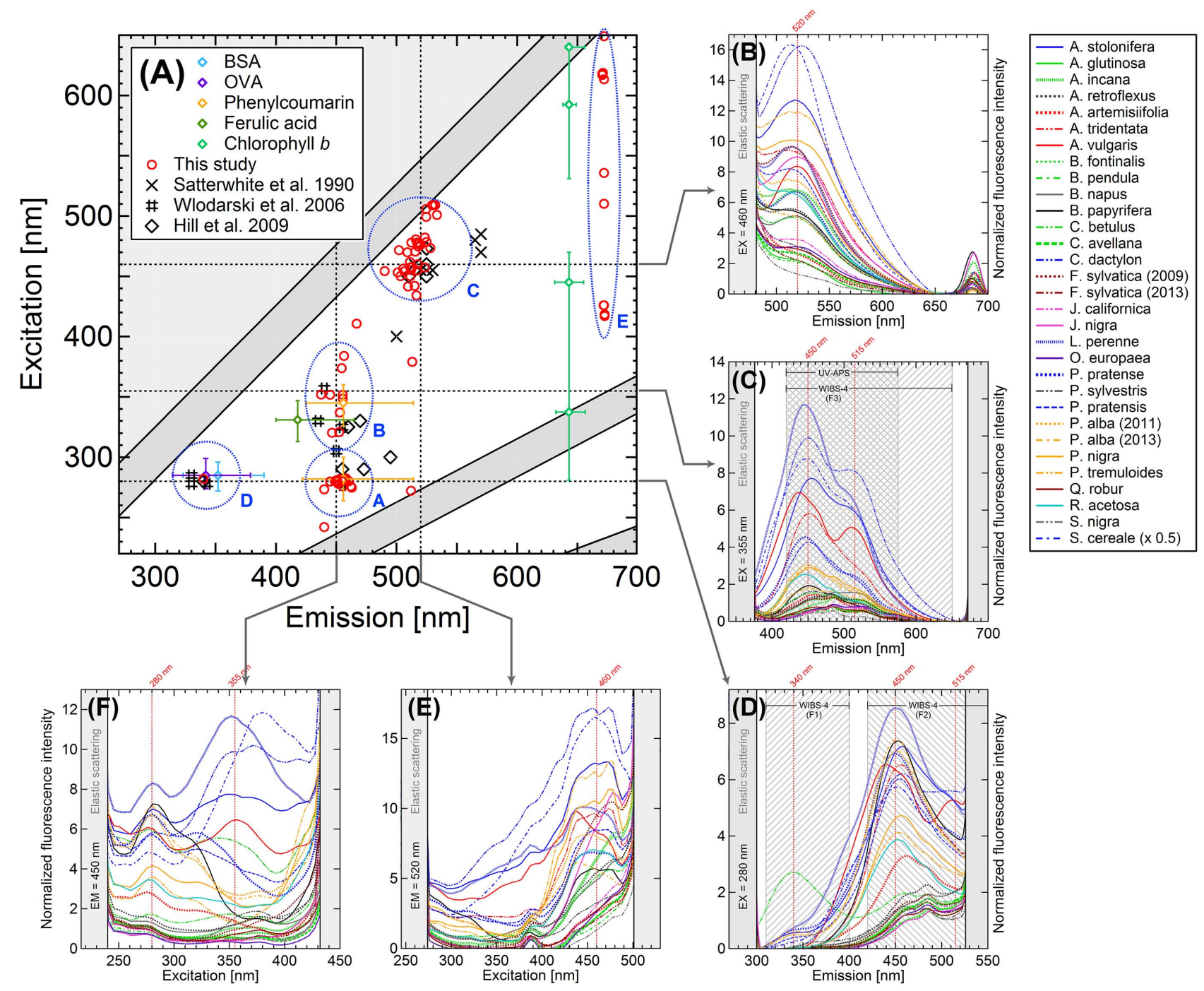

Fig. 5. Overview figure displaying autofluorescence fingerprint of dry pollen. (A) EEM summarizes spectral locations of fluorescence modes for all pollen species analyzed in this study (red markers) and data from previous reports (black markers) (Satterwhite, 1990; Wlodarski et al., 2006; Hill et al., 2009). Locations of fluorescence modes A-E are represented by blue circles. Also shown are spectral locations of selected pure fluorophores (proteins BSA and OVA; ferulic acid and phenylcoumarin as phenolic proxies; chlorophyll $b$ ) for direct comparison. For pure fluorophores, full width half maximum (FWHM) of emission signals is shown as horizontal and vertical bars (see also Pöhlker et al., 2012). (B-F) Normalized two-dimensional fluorescence spectra for selected excitation $\left(\lambda_{\mathrm{ex}}=280,355\right.$, and $\left.460 \mathrm{~nm}\right)$ and emission wavelengths $\left(\lambda_{\mathrm{em}}=450\right.$ and $520 \mathrm{~nm}$ ). These wavelengths have been chosen because (i) they centrally cross the pollen modes A-E, (ii) they cover spectral regions of high biofluorophore density, and (iii) they represent or approximate common excitation sources for FBAP-detection instruments (Pöhlker et al., 2012). Taxonomic affiliation of pollen on family level is represented as color code (see legend here and Fig. 7). Fluorescence spectra are normalized and therefore intensities can be compared across all species. Note that intensity of $S$. cereale is divided by factor 2 in all spectra. Shaded areas in (C) and (D) represent emission bands of LIF detectors UV-APS and WIBS-4.

plant photosynthesis, where they act as light-harvesting pigments (Taiz and Zeiger, 2010). In cell walls (e.g., in pollen), they are part of the "natural sunscreen" providing UVradiation protection and they also act as reactive oxygen species scavengers (Barrell et al., 2010). The pollen sporoderm is known as an accumulation site for carotenoid pigments, such as $\alpha$ - and $\beta$-carotene and lutein (e.g., Prahl et al., 1985; Kano and Hamaguchi, 2006). Together with flavonoids, they cause the typical yellow to orange color and their abundance in the pollen coat shows taxonomic specificity (Schulte et al., 2009). The reported absorption maximum of carotenoids is located at $\sim 480 \mathrm{~nm}$ (here $\lambda_{\text {ex,max }}=\sim 460 \mathrm{~nm}$ ) and therefore mode $C$ is inefficiently excited by UV-light (Sufra et al., 1977). Accordingly, dualor multi-wavelength excitation is most appropriate to address the carotenoid and phenolic features of pollen fluorescence. 
In contrast, single-wavelength excitation, usually in the UVrange, misses the main peak of the pollen carotenoid emission (compare Fig. 5e).

In addition to the strong and abundant signals $\mathrm{A}-\mathrm{C}$, the modes D (280/340) and E (350-650/675) occur in some pollen species. The weak mode $\mathrm{E}$ is attributed to chlorophyll $a$ ( $\mathrm{chl} a$ ) fluorescence which has been found in pollen previously (e.g., O'Connor et al., 2011). The individual chlorophyll pigment types (i.e., chl $a$, chl $b$, chl $c$, and $\mathrm{chl} d$ ) show different fluorescence properties (Welschmeyer, 1994; Moberg et al., 2001). For instance, chl $a$ reveals its main emission at $\sim 670 \mathrm{~nm}$ whereas chl $b$ emits at $\sim 650 \mathrm{~nm}$ (French et al., 1956). All of them reveal comparably wide excitation ranges (Pöhlker et al., 2012). We found chl $a$ fluorescence in grass and weed pollen species (e.g., A. vulgaris, L. perenne) but at a very low intensity level. One explanation for the presence of chlorophyll in pollen is the cytoplasmic inheritance of chloroplast DNA, which is independent of the nuclear chromosomes and occurs via pollen dispersal for some species (McCauley et al., 2007; Miko, 2008). Thus, the presence of chloroplasts in the course of paternal cytoplasmic gene transmission can explain the presence of chlorophyll in some species (e.g., Hipkins et al., 1994). However, microscopic evidence for chloroplasts in pollen grains has not been observed in the current study, which can be explained either by the absence of chloroplasts or inappropriate filter settings in the fluorescence microscopy analysis. An alternative explanation for the chlorophyll signal is the presence of chlorophyll molecules, which may occur in free state or bound to the pollen cell wall. It has been shown that the presence of chlorophyll pigments depends on the pollen maturation state, with higher chlorophyll abundance in immature pollen grains (Roshchina, 2003, 2004).

Mode D is attributed to protein fluorescence, which is mainly caused by the amino acid tryptophan with fluorescence at 280-295/340-353 nm (Pöhlker et al., 2012). For comparison, Fig. 5a shows the emission signals of the proteins bovine serum albumin (BSA) and ovalbumin (OVA), which clearly overlap with mode D. Protein autofluorescence is an omnipresent and characteristic feature in PBAP and has been observed for many organisms (e.g., Sivaprakasam et al., 2004; Kopczynski et al., 2005; Wlodarski et al., 2006; Hill et al., 2009). Furthermore, several bioaerosol detectors are designed to selectively excite and detect protein fluorescence (e.g., WIBS; compare Fig. 5d). It is therefore, perhaps, somewhat surprising that only one pollen type measured in the dry state (C. betulus, see Fig. 5d), among all analyzed 25 species, showed a clearly resolved protein mode, despite the fact that proteins and enzymes can constitute up to $\sim 60 \%$ of dry pollen weight (e.g., Roulston and Cane, 2000; Andrada and Telleria, 2005). Four grass pollen species (e.g., A. stolonifera and L. perenne) also show a shoulder-like signal for mode $\mathrm{D}$, indicating the presence of weak protein fluorescence (see Fig. 5d).
The absence of a clear protein signal can be related to UVlight shielding properties of the pollen sporoderm. About 95$99 \%$ of the incoming UV-radiation usually does not reach the cytosol because of sporoderm reflection (elastic scattering), fluorescence (inelastic scattering) and absorption (thermal energy dissipation). However, fluorescence and absorption can be regarded as linked processes that only differ in the extent the imparted energy is re-emitted as radiative vs. thermal energy (Lakowicz, 1999). Thus, in pollen grains with highly absorbing sporoderms, proteins and coenzymes that are located in the cytoplasm are not accessible to UV-excitation light. So, when measuring bulk properties of dry pollen by fluorescence spectroscopy, fluorescence from sporoderm pigments dominates EEM features, swamping any contribution from cytosolic fluorophores. In contrast, fluorescence microscopy of single pollen grains has the benefit of spatially resolving emission, thus showing the strong fluorescence from cell wall components, while also showing fluorescence from the cytosol (Sect. 3.1).

Carpinus betulus is the only exception we observed to this trend, which is because it shows a clear protein signal in its EEM (see Fig. 4f). The fluorescence microscopy image of C. betulus pollen in Fig. 6 provides a potential explanation for this "anomaly". It can be seen that the larger pollen grains $(\sim 35 \mu \mathrm{m})$, which show a yellowish fluorescence, occur as agglomerates with many smaller particles $(\sim 4 \mu \mathrm{m})$ showing strong bluish fluorescence. The fluorescence microscopic appearance of the larger $C$. betulus grains resembles the micrographs of other species in Fig. 2. Therefore, we assume that the "contaminating" small particles cause the unusual protein signals on top of the pollen-related modes in the EEM. The origin and identity of the small adhered particles is unclear. They exhibit a biological morphology with a cell wall-like structure that is the main origin of the blue emission. A contamination with microorganisms (i.e., bacteria) appears to be unlikely because of the comparably large particle size. Further, it also appears unlikely that the adhered particles are cytosolic starch granules from pollen grain rupture because of substantial differences in particle size and the absences of ruptured grains in the C. betulus sample (Fig. S5). One explanation would be the presence of many small immature pollen grains associated with the larger and mature ones. It is known that pollen fluorescence properties change during grain maturation and, particularly, with increasing contents of carotenoids in the sporoderm (causing green-yellow fluorescence), which is consistent with Fig. 6 (Roshchina, 2003). However, a detailed investigation of the identity of the adhered particles is beyond the scope of this study. It can be concluded that fluorescence from all analyzed pollen species lacks clear cytosol contributions (i.e., from proteins) and that the only exception to this general trend exhibits an obvious, and probably causative, morphological anomaly. This strengthens our hypothesis that the fluorescence signature of pollen is exclusively shaped by a set of light-accessible fluorophores in the pollen sporoderm. 


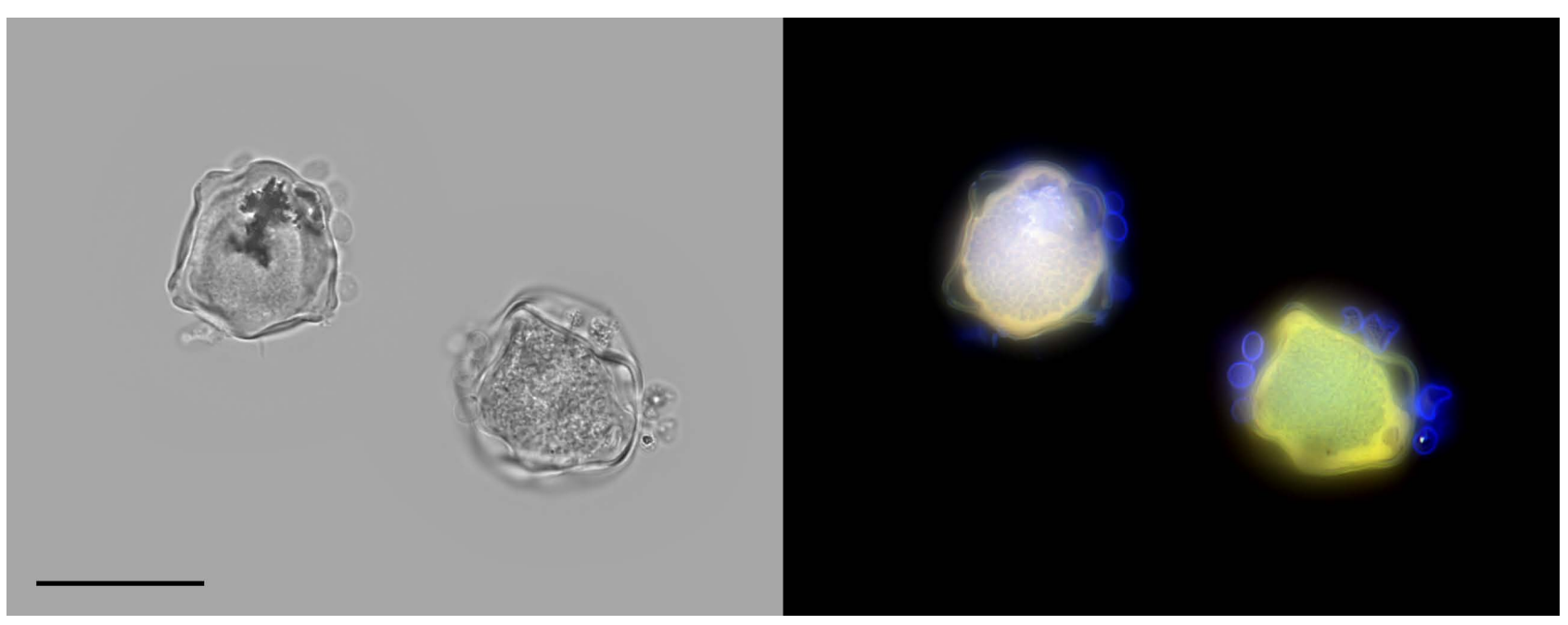

Fig. 6. Microscopy images of Carpinus betulus pollen in bright field (left) and fluorescence mode (right). Fluorescence image shown as overlay of three channels. Pollen were prepared in immersion oil. Micrographs illustrate small blue fluorescing particles adhering to pollen grains. Small particles shown here are representative for entire sample. Further microscopy images are shown in Fig. S5. Scale bar $=30 \mu m$.

\subsection{Taxonomic trends in the autofluorescence signature}

The mixtures of secondary plant metabolites in the pollen sporoderm, such as phenolics and flavonoids (Bate-Smith, 1962; Molgaard and Ravn, 1988) as well as carotenoids (Schulte et al., 2009), show taxonomic specificity. Thus, it is not surprising that the sporoderm-based fluorescence also exhibits certain taxonomic trends, as observed in our experiments. The Fig. 5b-f panels illustrate differences in fluorescence mode abundance and intensity across pollen species for selected excitation $\left(\lambda_{\mathrm{ex}}=280,355,460 \mathrm{~nm}\right.$; Fig. $\left.5 \mathrm{~b}-\mathrm{d}\right)$ and emission wavelengths $\left(\lambda_{\mathrm{em}}=450\right.$, and $520 \mathrm{~nm}$ Fig. $5 \mathrm{f}$ and e). The following general observations were made: (i) grass pollen belonging to the family Poaceae (blue) clearly show the highest intensities for both the phenolic and carotenoid fluorescence modes A-C. This is consistent with studies showing that plant tissue of Poaceae shows particularly high contents of phenolic compounds and elevated blue-green fluorescence, compared to other families (Lichtenthaler and Schweiger, 1998). (ii) The shrub pollen belonging to the family Asteraceae (red) also show comparably high intensities for all modes. (iii) Medium intensities were found for tree pollen of Salicaceae (yellow) and shrub pollen of Polygonaceae (cyan). (iv) There is a larger number of (mostly tree) pollen families (e.g., Betulaceae in green, Fagaceae in brown, and Oleaceae in violet) that reveal low fluorescence intensities in the entire EEM range. In general, the overall intensity level (averaged intensities of modes $\mathrm{A}-\mathrm{C}$ ) is a distinctive feature across pollen families, with grass pollen (i.e., Poaceae) fluorescence being highest and tree pollen (e.g., Betulaceae) fluorescence being lowest. Thus, the intensities of the modes $\mathrm{A}, \mathrm{B}$, and $\mathrm{C}$ are linked and show a clear positive correlation $(R=0.74-0.87)$ (see Fig. S6). However, in addition to this general intensity trend, the relative contributions of the individual modes A-C are variable across pollen families, as outlined in the following paragraph.

We utilized principal component analysis (PCA) to visualize general taxonomic trends in pollen fluorescence properties, as observed in Fig. 5. PCA reduces complex datasets to fewer dimensions and preserves most of the variability. It often provides insights into general underlying structures of the dataset in question. In other words, the PCA in this study is an attempt to display the diverse autofluorescence and morphology properties of pollen, based on a few basic parameters. Figure 7 displays three PCA bi-plots that illustrate taxonomic trends based on fluorescence data only (Fig. 7a), fluorescence data in combination with pollen grain size (Fig. 7b), and fluorescence data in combination with pollen grain size and shape (Fig. 7c) (Sect. 2.4).

In Fig. 7a two principal components (PC) span the fluorescence variability of all analyzed pollen species and the four eigenvectors shown (total intensity as well as relative intensities of the modes A, B, and C) represent the main distinctive features. It can be seen that (i) the intensity eigenvector spreads out the pollen species according to their overall fluorescence intensity, with Poaceae being highest, followed by Asteraceae as well as Salicaceae, and Betulaceae being lowest. (ii) The diametric eigenvector for mode $\mathrm{A}$ and mode $\mathrm{C}$ spread the pollen according to their fluorescence mode patterns. For example, the species J. nigra and B. fontinalis are characterized by a strongly fluorescent mode $\mathrm{C}$ and the absence of mode A (see Fig. $4 \mathrm{~d}$ and g). In contrast, B. papyrifera and $P$. alba exhibit a dominant mode $\mathrm{A}$ and a rather weak intensity for mode C (see Fig. 4e and Fig. S4n). (iii) In addition, a certain clustering of species from the same family 
(A) Fluorescence only

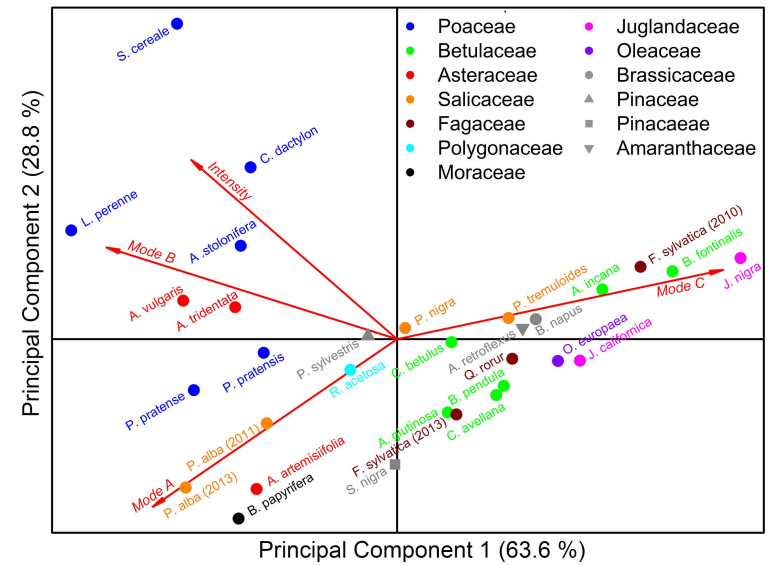

(B) Fluorescence and size

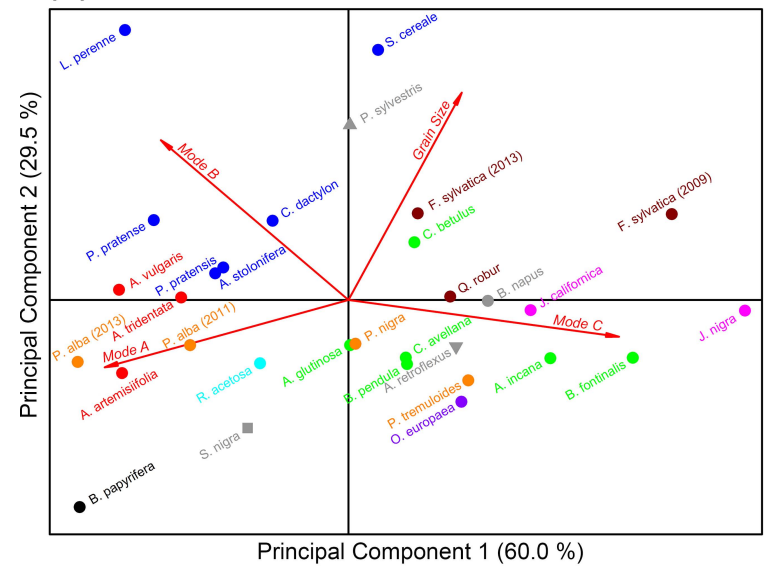

(C) Fluorescence, size, and shape

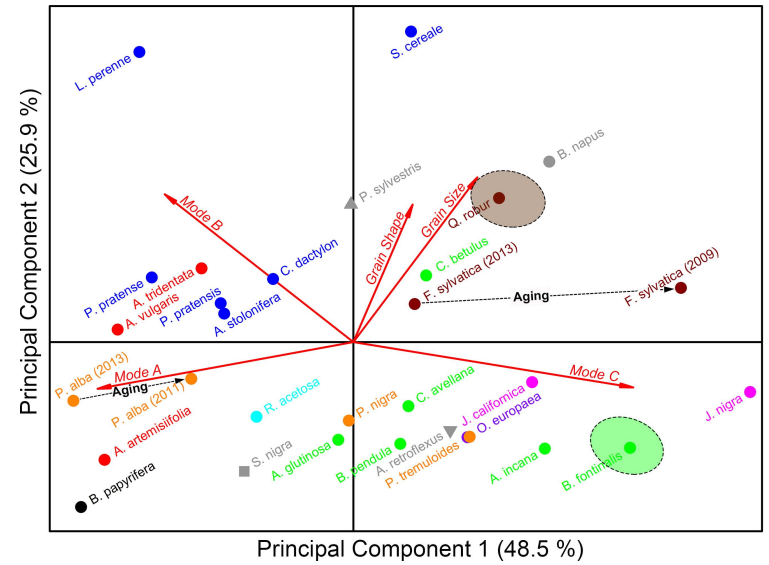

Fig. 7. Results of principal component analysis (PCA) illustrating taxonomic trends in pollen autofluorescence. Markers represent average properties of individual pollen species. (A) Bi-plot with scores of PCA based on pollen fluorescence properties only. Eigenvectors (red arrows) represent relative intensities of modes A-C and total intensity level, as most distinctive features. (B) Bi-plot with scores of PCA based on pollen fluorescence properties and size. Eigenvectors represent relative intensities of modes A-C and pollen grains diameter (Table 1). (C) Bi-plot with scores of PCA based on pollen fluorescence properties, grain size, and grains shape. Eigenvectors represent relative intensities of modes A-C, pollen grains diameter, and pollen axis aspect ratio as a measure for grain shape (Table 1). Black dashed arrows in (C) illustrate effect of aging for Fagus sylvatica and Populus alba (see Sect. 2.1, Figs. S2 and S3). Dashed elliptic circles for the two representative species Betula fontinalis and Quercus robur in (C) are semi-quantitative illustration of heterogeneity in morphology and fluorescence properties on single particle level (compare Sects. 3.1 and 3.3). Dimension of ellipses in direction of size eigenvector represent average grain diameter \pm SD (see Table 1). Dimension of ellipses in direction of mode $\mathrm{C}$ eigenvector represent normalized fluorescence intensity of mode $\mathrm{C} \pm 20 \%$. Note that the location of Carpinus betulus in the PCA plots is potentially influenced by the "contaminating" adhered particles in the sample (Sect. 3.2). 
is present in the bi-plot; however, not all pollen families are clearly separated.

In order to increase the taxonomic resolution in the PCA bi-plot, the autofluorescence-based input data is complemented by pollen grain size and shape as morphology-related parameters in dry state. Size and shape can vary substantially across pollen species with diameters ranging from $\sim 10 \mu \mathrm{m}$ to $\sim 50 \mu \mathrm{m}$ and an axis aspect ratio (major/minor axes) ranging from $\sim 1$ (spherical grains) to $\sim 1.8$ (elongated grains) (Table 1, Fig. S7). About $90 \%$ of the species in this study reveal rather spherical pollen grains (aspect ratio 1.1-1.2) and many species show grain diameters at about $25 \mu \mathrm{m}$ (Fig. S7). Thus, the parameters size and shape alone do not provide a clear specificity and separation of pollen families. The combination of autofluorescence- and morphology-related parameters increases the separation and the clustering of pollen families, as shown in Fig. $7 b$ and c. Here, pollen grain size yields a clear improvement whereas grain shape has only a minor effect. In Fig. 7b and c, pollen families cluster in different sectors of the PCA bi-plot (e.g., clear separation of Poaceae, Fagaceae, and Juglandaceae), however, with some overlapping regions (e.g., Poaceae and Asteraceae).

We can conclude that the PCA representation provides a good categorization of the characteristic autofluorescence and morphology parameters of pollen. Autofluorescence, size, and shape are the basic parameters for online LIF instrumentation. Thus, the trends and overall separation of species in Fig. 7 may be helpful to develop algorithms for pollen recognition in online applications. However, it should be kept in mind that the situation is complicated by two further effects. First, environmental influences (i.e., water) and pollen aging (compare Sect. 2.1) can change the fluorescence and morphology properties. The examples $P$. alba and $F$. sylvatica clearly illustrate the influence of age, which impacts the positioning in the PCA bi-plot. For both species the relative intensity of mode $\mathrm{C}$ increases with age (compare Fig. S3) and therefore the markers in the PCA bi-plot are shifted along the mode $\mathrm{C}$ eigenvector (illustrated by black arrows in Fig. 7c). Second, differences in fluorescence properties on single particle level cause further uncertainty in the PCA positioning (see Sect. 3.1). The defined positions in Fig. 7 represent the average properties of the pollen bulk samples, whereas the heterogeneity on single particle level may be more adequately represented by more diffuse spots, as illustrated for B. fontinalis and $Q$. robur in Fig. 7c. Ultimately, we suggest that the general trends and clustering in Fig. 7 represent a stable separation of different pollen species. As a next step, this observation should be reviewed by a systematic single particles analysis (online LIF or single particle fluorescence microscopy) to evaluate the level of confidence for pollen recognition.

\subsection{Relevance for ambient pollen measurements}

Currently, pollen monitoring and forecasting is still a manual and labor-intensive business based on pollen sampling and microscopy analysis. There is common interest in improving the pollen monitoring strategy in the direction of automated real-time techniques, which can provide statistically reliable and specific pollen measurements. Various approaches from different scientific directions are addressing this aspect (e.g., Ronneberger et al., 2002; Scharring et al., 2006; Ranzato et al., 2007; Skjoth et al., 2013). In the following section, we briefly review and discuss the applicability and limitations of autofluorescence-based techniques to real-time pollen analysis, based on the results of the present and previous studies.

The extent of selectivity that autofluorescence can provide in PBAP detection is still an open question and discussed on three selectivity levels: (i) discrimination between biological and nonbiological particles (e.g., PBAP vs. mineral dust), (ii) discrimination among bioaerosol particles and their classification into a certain number of metaclasses (e.g., bacteria, fungal spores, algae, and pollen), and (iii) identification of specific organisms on family, genus or even species level (Hill et al., 1999). It is commonly accepted that autofluorescence can reliably distinguish between biological and nonbiological particles in scenarios with limited influence by anthropogenic aerosol (Pan et al., 2007). On this first level of selectivity, quantification of FBAP and monitoring of its variability in ambient air is feasible, however, mostly without information about FBAP identity (e.g., Huffman et al., 2012; Toprak and Schnaiter, 2013). In this context, singleparticle LIF instruments usually rely on the detection of total (spectrally undispersed) fluorescence in comparably broad emission bands from one or two excitation wavelengths (e.g., Hairston et al., 1997; Foot et al., 2008). On the second level of selectivity, classification of bioaerosols is desired and has been addressed in many studies (e.g., Hill et al., 1999; Pinnick et al., 2004; Pan et al., 2009, 2010; Sivaprakasam et al., 2009). An increase of "resolving power" requires recording of a larger array of fluorescence information from single particles. This can be realized either on the excitation (i.e., multi-wavelength excitation) or on the emission axis (i.e., spectral dispersion). Instruments relying on spectrally dispersed fluorescence have proven to provide a stable classification of ambient FBAP with distinct spectral signatures (e.g., Pan et al., 2009, 2010), but are not commercially available and generally extremely expensive. On the third level of selectivity, bioaerosol identification is desired. However, several reports argue that this is beyond the scope of LIF instruments, with a few exceptional cases (Sivaprakasam et al., 2004; Pan et al., 2007). This can be explained by the fact that relatively few fluorophores (i.e., amino acids and coenzymes) determine the shape of the fluorescence signal of many organisms. For instance, a large number of bacterial species exhibits similar and comparably featureless fluorescence spectra and therefore cannot be discriminated (Hill et al., 1999, 
2009). Thus, the abundance, diversity and light accessibility of the underlying fluorophores is a crucial and limiting factor for the selectivity of LIF-based techniques.

Autofluorescence based, real-time monitoring of pollen clearly requires taxonomic selectivity for the detection of a minority population of few allergenic pollen species (approx. 10-20) on top of a complex and highly variable aerosol background. Several studies have indicated that the pollen fluorescence signal may be sufficiently specific for pollen differentiation (e.g., Willemse, 1972; Driessen et al., 1989; Satterwhite, 1997; Butkhuzi et al., 2002; O'Connor et al., 2011). Ronneberger et al. (2002) confirmed that offline techniques, such as high-resolution fluorescence microscopy, can provide a high pollen recognition rate $(>90 \%)$ based on the 3-D fluorescence distribution inside the pollen grains. Mitsumoto et al. $(2009,2010)$ were the first to confirm the online practicability of fluorescence-based pollen recognition for a set of five species. Their experiments are based on pollen sizing (via elastic light-scattering) and determining of the ratio of blue $\left(\Delta \lambda_{\text {em }}\right.$,blue $\left.=400-550 \mathrm{~nm}\right)$ to red $\left(\Delta \lambda_{\text {em,red }}=560-700 \mathrm{~nm}\right)$ fluorescence when excited with UV-light $\left(\lambda_{\mathrm{ex}}=350-380 \mathrm{~nm}\right)$. Their successful pollen discrimination is consistent with Fig. 7, showing a taxonomic clustering based on grain size and the ratio of fluorescence modes. Pan et al. (2011) reported the online detection of emission wavelength dispersed fluorescence spectra from two excitation wavelengths $\left(\lambda_{\text {ex }, 1}=263, \lambda_{\text {ex }, 2}=351 \mathrm{~nm}\right)$ and showed spectral differences across twelve pollen species. Their results are in good agreement with the autofluorescence signature reported here. For instance, a dominant peak at $\sim 450 \mathrm{~nm}$ (phenolics) occurred for the majority of species and additional signals at $\sim 340 \mathrm{~nm}$ (protein) and at $\sim 520 \mathrm{~nm}$ (carotenoid) are observed occasionally. Figure $5 \mathrm{c}$ and d confirms that, for UV-excitation, phenolic fluorescence is predominant. Moreover, the intensities of the online spectra reflect the taxonomic trends reported in Fig. 7; species of the families Poaceae (i.e., corn, meadow oat) and Asteraceae (e.g., Ragweed) were found to exhibit the highest intensities, whereas Betulaceae species (i.e., birch) shows substantially weaker fluorescence. Consequently, the results of these initial online LIF measurements and the offline results reported in this study are in good agreement. This underlines that offline and online instrumentation is measuring the same pollen-specific autofluorescence signature.

We suggest that our study can support the development and operation of LIF instruments for specific pollen monitoring in ambient air. Particularly, Fig. 5 can serve as a roadmap to select the most appropriate excitation wavelengths and emission bands, which provide good signal-to-noise ratios and the highest level of selectivity. In terms of ambient applicability the following aspects can be concluded: (i) pollen exhibit an autofluorescence fingerprint which is intrinsically different from bacteria and fungal spores (Hill et al., 2009), based on the fact that it does not originate from proteins and other cytosolic compounds but rather from cell wall asso- ciated fluorophores. This enables an autofluorescence-based differentiation of pollen from other PBAP types in the atmosphere, particularly when combined with particle sizing. (ii) Moreover, a classification of different pollen species is, in principle, practicable, as illustrated in Fig. 7. The most distinctive features are the overall fluorescence intensity as well as the occurrence and strength of the phenolic mode A and the carotenoid mode $\mathrm{C}$. In addition, differences in pollen grain size and shape can support a taxonomic discrimination. One remarkable example is the clear separation of grass (Poaceae) and tree pollen species (e. g., Betulaceae) in Fig. 7 , which both represent important aeroallergens. The separation of other pollen families is less clear and the extent of clustering vs. overlap has to be addressed in further studies. (iii) It should be kept in mind that the reported EEMs represent bulk spectra, which average the specific fluorescence properties of individual pollen grains. The fluorescence microscopy analysis in this study has shown a substantial diversity on pollen grain level in terms of fluorescence intensity, intracellular fluorophore distribution, and emission wavelength. Therefore, ambient applications, which mostly are operated as single particle detectors, must take this heterogeneity into account. Another layer of complexity involves the influence of environmental factors (e.g., relative humidity or chemical and physical aging) on pollen autofluorescence and morphology. Such phenomena are beyond the scope of the present study, however.

\section{Conclusions}

This study provides a characterization of the origin, properties, and selectivity of the autofluorescence from native pollen. It utilizes fluorescence microscopy and spectroscopy for the analysis of 31 pollen species. The experimental results are complemented with a synthesis of related literature knowledge. We show that full-field fluorescence microscopy is a simple and valuable tool for histological studies on single pollen grains. This allows the exploration of the intracellular distribution of intrinsic fluorophores in pollen. We found diverse morphological fluorescence properties across pollen species with fluorescent emission from the cell wall, the cytosol, and certain organelles. In addition, a remarkable heterogeneity of fluorescence intensity and emission wavelength across grains of the same species was observed. It can be concluded that the fluorescence micro-architecture of pollen grains is very complex and likely influenced strongly by maturation and metabolic state.

Fluorescence spectroscopy was utilized to record EEMs that exhibit a steady-state autofluorescence fingerprint of individual pollen species. The EEMs revealed a characteristic, reproducible signature of five fluorescence modes across all pollen samples, which could be attributed to four different fluorophore classes, namely phenolic compounds, carotenoid pigments, proteins and chlorophyll $a$. The most characteristic 
fluorescence originates from cell wall associated phenolics $\left(\lambda_{\mathrm{ex}}=\sim 280\right.$ and $\left.355 \mathrm{~nm} / \lambda_{\mathrm{em}}=\sim 450 \mathrm{~nm}\right)$ and carotenoids $(\sim 460 / 520)$. Weak chlorophyll $a(\sim 350-650 / 675)$ and protein $(\sim 280 / 340)$ fluorescence was observed occasionally for certain species. We found that the cell wall associated fluorophores dominate the fluorescence signatures of dry pollen. The abundance of fluorophores in the pollen sporoderm is species-specific, and therefore, sporoderm-related fluorescence signals show certain taxonomic trends. Principal component analysis was used to explore the discrimination potential of pollen autofluorescence and revealed a differentiation of pollen on family level.

We show that the autofluorescence of pollen is intrinsically different from bacteria and fungal spores, based on the fact that it does not originate from proteins and other cytosolic compounds, but rather from cell wall associated fluorophores. Moreover, a classification of pollen species based on their EEMs is, in principle, practicable. The most distinctive spectral features are the overall fluorescence intensity as well as the occurrence and strength of the phenolic and carotenoid modes. However, fluorescence microscopy reveals that pollen can show widely variable fluorescence intensity, intra-cellular fluorophore distribution, and emission wavelength between individual grains. This highlights that EEM spectra are averages of bulk pollen and not necessarily representative of individual particles. Accordingly, it is important to understand and apply this heterogeneity to the analysis of techniques that utilize autofluorescence from single particles. Ultimately, we suggest that the results reported here can support the development and operation of LIF instruments for specific pollen monitoring in ambient air and further help to explore the levels of selectivity that autofluorescence-based techniques can provide in PBAP analysis.
Appendix A. List of frequently used acronyms.

\begin{tabular}{ll}
\hline Acronym & Description \\
\hline BP & band-pass \\
BSA & bovine serum albumin \\
BWA & biological warfare agent \\
CCD & charge-coupled device \\
CCN & cloud condensation nuclei \\
DAPI & 4',6-diamidino-2-phenylindole \\
DNA & deoxyribonucleic acid \\
EEM & excitation-emission matrix \\
FBAP & fluorescent biological aerosol particles \\
FM & fluorescence microscopy \\
FS & fluorescence spectroscopy \\
FWHM & full width half max \\
GFP & green fluorescent protein \\
IN & ice nuclei \\
INA & ice nucleation activity \\
LIF & laser/light induced fluorescence \\
NF & normalization factor \\
OVA & ovalbumin \\
PAH & polycyclic aromatic hydrocarbons \\
PBAP & primary biological aerosol particles \\
PC & principal component \\
PCA & principal component analysis \\
RNA & ribonucleic acid \\
SD & standard deviation \\
SOA & secondary organic aerosol \\
UV & ultraviolet \\
UV-APS & ultraviolet aerodynamic particle sizer \\
WIBS & wideband integrated bioaerosol sensor \\
&
\end{tabular}

Supplementary material related to this article is
available online at http://www.atmos-meas-tech.net/6/
3369/2013/amt-6-3369-2013-supplement.pdf.

Acknowledgements. This work has been funded by the Max Planck Society, the Max Planck Graduate Center with the Johannes Gutenberg-Universität Mainz (MPGC), and the LEC Geocycles Mainz. J. A. Huffman acknowledges internal faculty funding from the University of Denver. The authors gratefully acknowledge support by M. O. Andreae, A. Zimmer, K. Selzle, J. FröhlichNowoisky and I. Müller-Germann and helpful conversation with D. R. Huffman, B. Weber, and W. Elbert.

The service charges for this open access publication have been covered by the Max Planck Society.

Edited by: P. Herckes

\section{References}

Agranovski, V., Ristovski, Z., Hargreaves, M., Blackall, P. J., and Morawska, L.: Performance evaluation of the UVAPS: influence of physiological age of airborne bacteria and bacterial 
stress, J. Aerosol Sci., 34, 1711-1727, doi:10.1016/s00218502(03)00191-5, 2003.

Andrada, A. C. and Telleria, M. C.: Pollen collected by honey bees (Apis mellifera L.) from south of Calden district (Argentina): botanical origin and protein content, Grana, 44, 115122, doi:10.1080/00173130510010459, 2005.

Andrade-Eiroa, A., Canle, M., and Cerda, V.: Environmental Applications of Excitation-Emission Spectrofluorimetry: An In-Depth Review I, Appl. Spectrosc. Rev., 48, 1-49, doi:10.1080/05704928.2012.692104, 2013.

Asbeck, F.: Fluoreszierender Blütenstaub, Naturwissenschaften, 42, 632-632, 1955.

Barrell, P. J., Wakelin, A. M., Gatehouse, M. L., Lister, C. E., and Conner, A. J.: Inheritance and Epistasis of Loci Influencing Carotenoid Content in Petal and Pollen Color Variants of California Poppy (Eschscholzia californica Cham.), J. Hered., 101, 750-756, doi:10.1093/jhered/esq079, 2010.

Bate-Smith, E. C.: The phenolic constituents of plants and their taxonomic significance, Jour. Linn. Soc. London Bot., 58, 95-173, 1962.

Bedinger, P. A., Hardeman, K. J., and Loukides, C. A.: Travelling in style: The cell biology of pollen, Trends Cell Biol., 4, 132-138, doi:10.1016/0962-8924(94)90068-x, 1994.

Bernstein, J. A., Alexis, N., Barnes, C., Bernstein, I. L., Nel, A., Peden, D., Diaz-Sanchez, D., Tarlo, S. M., and Williams, P. B.: Health effects of air pollution, J. Allergy and Clin. Immun., 114, 1116-1123, doi:10.1016/j.jaci.2004.08.030, 2004.

Boavida, L. C., Becker, J. D., and Feijo, J. A.: The making of gametes in higher plants, Int. J. Dev. Biol., 49, 595-614, doi:10.1387/ijdb.052019lb, 2005.

Bones, D. L., Henricksen, D. K., Mang, S. A., Gonsior, M., Bateman, A. P., Nguyen, T. B., Cooper, W. J., and Nizkorodov, S. A.: Appearance of strong absorbers and fluorophores in limoneneO-3 secondary organic aerosol due to NH4+-mediated chemical aging over long time scales, J. Geophys. Res.-Atmos., 115, D05203, doi:10.1029/2009jd012864, 2010.

Brooks, J. and Shaw, G.: Sporopollenin a review of its chemistry paleochemistry and geochemistry, Grana, 17, 91-98, 1978.

Bundke, U., Reimann, B., Nillius, B., Jaenicke, R., and Bingemer, H.: Development of a Bioaerosol single particle detector (BIO IN) for the Fast Ice Nucleus CHamber FINCH, Atmos. Meas. Tech., 3, 263-271, doi:10.5194/amt-3-263-2010, 2010.

Burrows, S. M., Elbert, W., Lawrence, M. G., and Pöschl, U.: Bacteria in the global atmosphere - Part 1: Review and synthesis of literature data for different ecosystems, Atmos. Chem. Phys., 9, 9263-9280, doi:10.5194/acp-9-9263-2009, 2009.

Butkhuzi, T., Kuchukashvili, Z., Sharvashidze, M., Natsvlishvili, G., and Gurabanidze, V.: Cytodiagnostics on intact pollen using photoluminescence, J. Biol. Phys. Chem., 2, 53-55, 2002.

Castro, A. J., Rejón, J. D., Fendri, M., Jiménez-Quesada, M. J., Zafra, A., Jiménez-López, M. I., Rodríguez-García, M. I., and Alché, J. D.: Taxonomical discrimination of pollen grains by using confocal laser scanning microscopy (CLSM) imaging of autofluorescence, in: Microscopy: Science, Technology, Applications and Education, edited by: Méndez-Vilas, A. and Díaz Álvarez, J., Formatex Research Center, Badajoz, Spain, 607-613, 2010.

D'Amato, G.: Urban air pollution and plant-derived respiratory allergy, Clin. Exp. Allergy, 30, 628-636, 2000.
Deguillaume, L., Leriche, M., Amato, P., Ariya, P. A., Delort, A.M., Pöschl, U., Chaumerliac, N., Bauer, H., Flossmann, A. I., and Morris, C. E.: Microbiology and atmospheric processes: chemical interactions of primary biological aerosols, Biogeosciences, 5, 1073-1084, doi:10.5194/bg-5-1073-2008, 2008.

Després, V. R., Huffman, J. A., Burrows, S. M., Hoose, C., Safatov, A. S., Buryak, G., Fröhlich-Nowoisky, J., Elbert, W., Andreae, M. O., Pöschl, U., and Jaenicke, R.: Primary biological aerosol particles in the atmosphere: a review, Tellus B, 64, 15598, doi:10.3402/tellusb.v64i0.15598, 2012.

Dickinson, H.: Dry stigmas, water and self-incompatibility in Brassica, Sex. Plant Reprod., 8, 1-10, 1995.

Diehl, K., Quick, C., Matthias-Maser, S., Mitra, S. K., and Jaenicke, R.: The ice nucleating ability of pollen - Part I: Laboratory studies in deposition and condensation freezing modes, Atmos. Res., 58, 75-87, doi:10.1016/s0169-8095(01)00091-6, 2001.

Diehl, K., Matthias-Maser, S., Jaenicke, R., and Mitra, S. K.: The ice nucleating ability of pollen: Part II. Laboratory studies in immersion and contact freezing modes, Atmos. Res., 61, 125-133, doi:10.1016/s0169-8095(01)00132-6, 2002.

Diethart, B., Sam, S., and Weber, M.: Walls of allergenic pollen: Special reference to the endexine, Grana, 46, 164-175, doi:10.1080/00173130701472181, 2007.

Dingle, A. N.: Pollens as condensation nuclei, J. Rech. Atmos., 2, 231-237, 1966.

Driessen, M., Willemse, M. T. M., and Vanluijn, J. A. G.: Grass-pollen grain determination by light-microscopy and UVmicroscopy, Grana, 28, 115-122, 1989.

Elbert, W., Taylor, P. E., Andreae, M. O., and Pöschl, U.: Contribution of fungi to primary biogenic aerosols in the atmosphere: wet and dry discharged spores, carbohydrates, and inorganic ions, Atmos. Chem. Phys., 7, 4569-4588, doi:10.5194/acp-7-4569-2007, 2007.

Ferri, A., Giordani, E., Padula, G., and Bellini, E.: Viability and in vitro germinability of pollen grains of olive cultivars and advanced selections obtained in Italy, Adv. Hortic. Sci., 22, 116122, 2008.

Foot, V. E., Kaye, P. H., Stanley, W. R., Barrington, S. J., Gallagher, M., and Gabey, A.: Low-cost real-time multi-parameter bio-aerosol sensors, Proc. SPIE - Int. Soc. Opt. Eng., 7116, 112, doi:10.1117/12.800226, 2008.

Franze, T., Weller, M. G., Niessner, R., and Pöschl, U.: Protein nitration by polluted air, Envir. Sci. Tech., 39, 1673-1678, doi:10.1021/es0488737, 2005.

French, C. S., Smith, J. H. C., Virgin, H. I., and Airth, R. L.: Fluorescence-spectrum curves of chlorophylls, pheophytins, phycoerythrins, phycocyanins and hypericin, Plant Physiol., 31, 369-374, 1956.

Fröhlich-Nowoisky, J., Pickersgill, D. A., Després, V. R., and Pöschl, U.: High diversity of fungi in air particulate matter, P. Natl. Acad. Sci. USA, 106, 12814-12819, doi:10.1073/pnas.0811003106, 2009.

Gabey, A. M., Stanley, W. R., Gallagher, M. W., and Kaye, P. H.: The fluorescence properties of aerosol larger than $0.8 \mu \mathrm{m}$ in an urban and a PBA-dominated location, Atmos. Chem. Phys. Discuss., 11, 531-566, doi:10.5194/acpd-11-531-2011, 2011.

Gabey, A. M., Gallagher, M. W., Whitehead, J., Dorsey, J. R., Kaye, P. H., and Stanley, W. R.: Measurements and comparison of primary biological aerosol above and below a tropical forest canopy 
using a dual channel fluorescence spectrometer, Atmos. Chem. Phys., 10, 4453-4466, doi:10.5194/acp-10-4453-2010, 2010.

Gabey, A. M., Vaitilingom, M., Freney, E., Boulon, J., Sellegri, K., Gallagher, M. W., Crawford, I. P., Robinson, N. H., Stanley, W. R., and Kaye, P. H.: Observations of fluorescent and biological aerosol at a high-altitude site in central France, Atmos. Chem. Phys., 13, 7415-7428, doi:10.5194/acp-13-7415-2013, 2013.

Gorbushina, A. A. and Broughton, W. J.: Microbiology of the Atmosphere-Rock Interface: How Biological Interactions and Physical Stresses Modulate a Sophisticated Microbial Ecosystem, Annu. Rev. Microbiol., 63, 431-450, 2009.

Grienenberger, E., Besseau, S., Geoffroy, P., Debayle, D., Heintz, D., Lapierre, C., Pollet, B., Heitz, T., and Legrand, M.: A BAHD acyltransferase is expressed in the tapetum of Arabidopsis anthers and is involved in the synthesis of hydroxycinnamoyl spermidines, Plant J., 58, 246-259, doi:10.1111/j.1365313X.2008.03773.x, 2009.

Griffiths, P. T., Borlace, J. S., Gallimore, P. J., Kalberer, M., Herzog, M., and Pope, F. D.: Hygroscopic growth and cloud activation of pollen: a laboratory and modelling study, Atmos. Sci. Lett., 13, 289-295, doi:10.1002/asl.397, 2012.

Hairston, P. P., Ho, J., and Quant, F. R.: Design of an instrument for real-time detection of bioaerosols using simultaneous measurement of particle aerodynamic size and intrinsic fluorescence, $\mathrm{J}$. Aerosol Sci., 28, 471-482, 1997.

Harris, P. J. and Hartley, R. D.: Phenolic constituents of the cellwalls of Monocotyledons, Biochem. Syst. Ecol., 8, 153-160, doi:10.1016/0305-1978(80)90008-3, 1980.

Hawe, A., Sutter, M., and Jiskoot, W.: Extrinsic fluorescent dyes as tools for protein characterization, Pharm. Res., 25, 1487-1499, doi:10.1007/s11095-007-9516-9, 2008.

Healy, D. A., O'Connor, D. J., Burke, A. M., and Sodeau, J. R.: A laboratory assessment of the Waveband Integrated Bioaerosol Sensor (WIBS-4) using individual samples of pollen and fungal spore material, Atmos. Environ., 60, 534-543, doi:10.1016/j.atmosenv.2012.06.052, 2012a.

Healy, D. A., O'Connor, D. J., and Sodeau, J. R.: Measurement of the particle counting efficiency of the "Waveband Integrated Bioaerosol Sensor" model number 4 (WIBS-4), J. Aerosol Sci., 47, 94-99, doi:10.1016/j.jaerosci.2012.01.003, 2012b.

Herbrich, S., Gehder, M., Krull, R., and Gericke, K. H.: Label-Free Spatial Analysis of Free and Enzyme-Bound NAD(P)H in the Presence of High Concentrations of Melanin, J. Fluoresc., 22, 349-355, doi:10.1007/s10895-011-0965-5, 2012.

Hill, S. C., Pinnick, R. G., Niles, S., Pan, Y. L., Holler, S., Chang, R. K., Bottiger, J., Chen, B. T., Orr, C. S., and Feather, G.: Realtime measurement of fluorescence spectra from single airborne biological particles, Field Anal. Chem. Tech., 3, 221-239, 1999.

Hill, S. C., Mayo, M. W., and Chang, R. K.: Fluorescence of bacteria, pollens, and naturally occurring airborne particles: excitation/emission spectra, Army report, ARL-TR-4722, Army Research Laboratory, Adelphi, MD, USA, 2009.

Hipkins, V. D., Krutovskii, K. V., and Strauss, S. H.: Organelle genomes in conifers: Structure, evolution, and diversity, Forest Genetics, 1, 179-189, 1994.

Ho, J.: Future of biological aerosol detection, Anal. Chim. Acta, 457, 125-148, 2002.

Hoose, C. and Möhler, O.: Heterogeneous ice nucleation on atmospheric aerosols: a review of results from laboratory experiments,
Atmos. Chem. Phys., 12, 9817-9854, doi:10.5194/acp-12-98172012, 2012.

Hoose, C., Kristjansson, J. E., and Burrows, S. M.: How important is biological ice nucleation in clouds on a global scale?, Environ. Res. Lett., 5, 1-7, doi:10.1088/1748-9326/5/2/024009, 2010.

Hoque, E. and Remus, G.: Natural UV-screening mechanisms of Norway spruce (Picea abies L Karst) needles, Photochem. Photobiol., 69, 177-192, doi:10.1111/j.1751-1097.1999.tb03272.x, 1999.

Huffman, J. A., Treutlein, B., and Pöschl, U.: Fluorescent biological aerosol particle concentrations and size distributions measured with an Ultraviolet Aerodynamic Particle Sizer (UVAPS) in Central Europe, Atmos. Chem. Phys., 10, 3215-3233, doi:10.5194/acp-10-3215-2010, 2010.

Huffman, J. A., Sinha, B., Garland, R. M., Snee-Pollmann, A., Gunthe, S. S., Artaxo, P., Martin, S. T., Andreae, M. O., and Pöschl, U.: Size distributions and temporal variations of biological aerosol particles in the Amazon rainforest characterized by microscopy and real-time UV-APS fluorescence techniques during AMAZE-08, Atmos. Chem. Phys., 12, 11997-12019, doi:10.5194/acp-12-11997-2012, 2012.

Huffman, J. A., Prenni, A. J., DeMott, P. J., Pöhlker, C., Mason, R. H., Robinson, N. H., Fröhlich-Nowoisky, J., Tobo, Y., Després, V. R., Garcia, E., Gochis, D. J., Harris, E., Müller-Germann, I., Ruzene, C., Schmer, B., Sinha, B., Day, D. A., Andreae, M. O., Jimenez, J. L., Gallagher, M., Kreidenweis, S. M., Bertram, A. K., and Pöschl, U.: High concentrations of biological aerosol particles and ice nuclei during and after rain, Atmos. Chem. Phys., 13, 6151-6164, doi:10.5194/acp-13-6151-2013, 2013.

Hutzler, P., Fischbach, R., Heller, W., Jungblut, T. P., Reuber, S., Schmitz, R., Veit, M., Weissenbock, G., and Schnitzler, J. P.: Tissue localization of phenolic compounds in plants by confocal laser scanning microscopy, J. Exp. Bot., 49, 953-965, doi:10.1093/jxb/49.323.953, 1998.

Jacobs, J. F., Koper, G. J. M., and Ursem, W. N. J.: UV protective coatings: A botanical approach, Prog. Org. Coat., 58, 166-171, doi:10.1016/j.porgcoat.2006.08.023, 2007.

Jeys, T. H., Herzog, W. D., Hybl, J. D., Czerwinski, R. N., and Sanchez, A.: Advanced trigger development, Linc. Lab. J., 17, 29-62, 2007.

Kalman, E. L., Winquist, F., and Lundstrom, I.: A new pollen detection method based on an electronic nose, Atmos. Environ., 31, 1715-1719, doi:10.1016/s1352-2310(96)00313-5, 1997.

Kanaani, H., Hargreaves, M., Ristovski, Z., and Morawska, L.: Performance assessment of UVAPS: Influence of fungal spore age and air exposure, J. Aerosol Sci., 38, 83-96, 2007.

Kanaani, H., Hargreaves, M., Smith, J., Ristovski, Z., Agranovski, V., and Morawska, L.: Performance of UVAPS with respect to detection of airborne fungi, J. Aerosol Sci., 39, 175-189, doi:10.1016/j.jaerosci.2007.10.007, 2008.

Kano, H. and Hamaguchi, H. O.: Vibrational imaging of a single pollen grain by ultrabroadband multiplex coherent anti-stokes Raman scattering microspectroscopy, Chem. Lett., 35, 1124 1125, doi:10.1246/cl.2006.1124, 2006.

Kaye, P. H., Stanley, W. R., Hirst, E., Foot, E. V., Baxter, K. L., and Barrington, S. J.: Single particle multichannel bio-aerosol fluorescence sensor, Opt. Express, 13, 3583-3593, 2005. 
Kellogg, C. A. and Griffin, D. W.: Aerobiology and the global transport of desert dust, Trends Ecol. Evol., 21, 638-644, doi:10.1016/j.tree.2006.07.004, 2006.

Kiselev, D., Bonacina, L., and Wolf, J.-P.: Individual bioaerosol particle discrimination by multi-photon excited fluorescence, Opt. Express, 19, 24516-24521, 2011.

Kopczynski, K., Kwasny, M., Mierczyk, Z., and Zawadzki, Z.: Laser induced fluorescence system for detection of biological agents: European project FABIOLA, Proc. SPIE-Int. Soc. Opt. Eng., 5954, 1-12, doi:10.1117/12.623013, 2005.

Kuehn, M. J. and Kesty, N. C.: Bacterial outer membrane vesicles and the host-pathogen interaction, Genes Dev., 19, 2645-2655, doi:10.1101/gad.1299905, 2005.

Kuparinen, A., Katul, G., Nathan, R., and Schurr, F. M.: Increases in air temperature can promote wind-driven dispersal and spread of plants, Proc. Roy. Soc. B-Biol. Sci., 276, 3081-3087, doi:10.1098/rspb.2009.0693, 2009.

Lakowicz, J. R.: Principles of Fluorescence Spectroscopy, Plenum publishers New York, 1999.

Lang, M., Stober, F., and Lichtenthaler, H. K.: Fluorescence emission-spectra of plant-leaves and plant constituents, Radiat. Environ. Bioph., 30, 333-347, doi:10.1007/bf01210517, 1991.

Lee, H. J., Laskin, A., Laskin, J., and Nizkorodov, S. A.: ExcitationEmission Spectra and Fluorescence Quantum Yields for Fresh and Aged Biogenic Secondary Organic Aerosols, Environ. Sci. Technol., 47, 5763-5770, doi:10.1021/es400644c, 2013.

Li, Z. H., Wang, Q. A., Ruan, X. A., Pan, C. D., and Jiang, D. A.: Phenolics and Plant Allelopathy, Molecules, 15, 8933-8952, doi:10.3390/molecules15128933, 2010.

Lichtenthaler, H. K. and Schweiger, J.: Cell wall bound ferulic acid, the major substance of the blue-green fluorescence emission of plants, J. Plant Physiol., 152, 272-282, 1998.

Mahowald, N., Ward, D. S., Kloster, S., Flanner, M. G., Heald, C. L., Heavens, N. G., Hess, P. G., Lamarque, J.-F., and Chuang, P. Y.: Aerosol Impacts on Climate and Biogeochemistry, in: Annual Review of Environment and Resources, Vol 36, edited by: Gadgil, A. and Liverman, D. M., Annual Review of Environment and Resources, 45-74, 2011.

McCauley, D. E., Sundby, A. K., Bailey, M. F., and Welch, M. E.: Inheritance of chloroplast DNA is not strictly maternal in Silene vulgaris (Caryophyllaceae): Evidence from experimental crosses and natural populations, Am. J. Bot., 94, 1333-1337, doi:10.3732/ajb.94.8.1333, 2007.

Miko, I.: Non-nuclear Genes and Their Inheritance, Nature Education, 1, 2008.

Mitsumoto, K., Yabusaki, K., and Aoyagi, H.: Classification of pollen species using autofluorescence image analysis, J. Biosci. Bioeng., 107, 90-94, doi:10.1016/j.jbiosc.2008.10.001, 2009.

Mitsumoto, K., Yabusaki, K., Kobayashi, K., and Aoyagi, H.: Development of a novel real-time pollen-sorting counter using species-specific pollen autofluorescence, Aerobiologia, 26, 99111, doi:10.1007/s10453-009-9147-1, 2010.

Moberg, L., Robertsson, G., and Karlberg, B.: Spectrofluorimetric determination of chlorophylls and pheopigments using parallel factor analysis, Talanta, 54, 161-170, 2001.

Möhler, O., DeMott, P. J., Vali, G., and Levin, Z.: Microbiology and atmospheric processes: the role of biological particles in cloud physics, Biogeosciences, 4, 1059-1071, doi:10.5194/bg-4-10592007, 2007.
Molgaard, P. and Ravn, H.: Evolutionary aspects of caffeoyl ester distribution in Dicotyledons, Phytochemistry, 27, 2411-2421, doi:10.1016/0031-9422(88)87005-5, 1988.

Morris, C. E., Sands, D. C., Vinatzer, B. A., Glaux, C., Guilbaud, C., Buffiere, A., Yan, S. C., Dominguez, H., and Thompson, B. M.: The life history of the plant pathogen Pseudomonas syringae is linked to the water cycle, Isme J., 2, 321-334, doi:10.1038/ismej.2007.113, 2008.

Mularczyk-Oliwa, M., Bombalska, A., Kaliszewski, M., Wlodarski, M., Kopczynski, K., Kwasny, M., Szpakowska, M., and Trafny, E. A.: Comparison of fluorescence spectroscopy and FTIR in differentiation of plant pollens, Spectrochim. Acta A, 97, 246-254, doi:10.1016/j.saa.2012.05.063, 2012.

Nepi, M. and Franchi, G. G.: Cytochemistry of mature angiosperm pollen, Plant Syst. Evol., 222, 45-62, doi:10.1007/bf00984095, 2000.

O’Connor, D. J., Iacopino, D., Healy, D. A., O’Sullivan, D., and Sodeau, J. R.: The intrinsic fluorescence spectra of selected pollen and fungal spores, Atmos. Environ., 45, 6451-6458, doi:10.1016/j.atmosenv.2011.07.044, 2011.

Pacini, E.: From anther and pollen ripening to pollen presentation, Plant Syst. Evol., 222, 19-43, doi:10.1007/bf00984094, 2000.

Pacini, E. and Hesse, M.: Pollenkitt - its composition, forms and functions, Flora, 200, 399-415, doi:10.1016/j.flora.2005.02.006, 2005.

Pan, Y. L., Eversole, J. D., Kaye, P. H., Foot, V., Pinnick, R. G., Hill, S. C., Mayo, M. W., Bottiger, J., Huston, A., Sivaprakasam, V., and Chang, R. K.: Bio-aerosol fluorescence - Detecting and characterising bio-aerosols via UV light-induced fluorescence spectroscopy, in: Optics of Biological Particles, edited by: Hoekstra, A., Maltsev, V., and Videen, G., NATO Science Series, Human Press/Springer, Dordrecht, 63-163, 2007.

Pan, Y. L., Pinnick, R. G., Hill, S. C., and Chang, R. K.: ParticleFluorescence Spectrometer for Real-Time Single-Particle Measurements of Atmospheric Organic Carbon and Biological Aerosol, Envir. Sci. Tech., 43, 429-434, doi:10.1021/es801544y, 2009.

Pan, Y.-L., Hill, S. C., Pinnick, R. G., Huang, H., Bottiger, J. R., and Chang, R. K.: Fluorescence spectra of atmospheric aerosol particles measured using one or two excitation wavelengths: Comparison of classification schemes employing different emission and scattering results, Opt. Express, 18, 12436-12457, doi:10.1364/oe.18.012436, 2010.

Pan, Y.-L., Hill, S. C., Pinnick, R. G., House, J. M., Flagan, R. C., and Chang, R. K.: Dual-excitation-wavelength fluorescence spectra and elastic scattering for differentiation of single airborne pollen and fungal particles, Atmos. Environ., 45, 1555-1563, doi:10.1016/j.atmosenv.2010.12.042, 2011.

Phillips, L.: Application of fluorescence microscopy to problem of derived pollen in British Pleistocene deposits, New Phytol., 71, 755-762, doi:10.1111/j.1469-8137.1972.tb01286.x, 1972.

Piffanelli, P., Ross, J. H. E., and Murphy, D. J.: Biogenesis and function of the lipidic structures of pollen grains, Sex. Plant Reprod., 11, 65-80, doi:10.1007/s004970050122, 1998.

Pinnick, R. G., Hill, S. C., Pan, Y. L., and Chang, R. K.: Fluorescence spectra of atmospheric aerosol at Adelphi, Maryland, USA: measurement and classification of single particles containing organic carbon, Atmos. Environ., 38, 1657-1672, doi:10.1016/j.atmosenv.2003.11.017, 2004. 
Pinnick, R. G., Fernandez, E., Rosen, J. M., Hill, S. C., Wang, Y., and Pan, Y. L.: Fluorescence spectra and elastic scattering characteristics of atmospheric aerosol in Las Cruces, New Mexico, USA: Variability of concentrations and possible constituents and sources of particles in various spectral clusters, Atmos. Environ., 65, 195-204, 2013.

Pöhlker, C., Huffman, J. A., and Pöschl, U.: Autofluorescence of atmospheric bioaerosols - fluorescent biomolecules and potential interferences, Atmos. Meas. Tech., 5, 37-71, doi:10.5194/amt-537-2012, 2012.

Pope, F. D.: Pollen grains are efficient cloud condensation nuclei, Environ. Res. Lett., 5, 044015, doi:10.1088/17489326/5/4/044015, 2010.

Pöschl, U.: Atmospheric aerosols: Composition, transformation, climate and health effects, Angew. Chem. Int. Edit., 44, 75207540, doi:10.1002/anie.200501122, 2005.

Pöschl, U., Martin, S. T., Sinha, B., Chen, Q., Gunthe, S. S., Huffman, J. A., Borrmann, S., Farmer, D. K., Garland, R. M., Helas, G., Jimenez, J. L., King, S. M., Manzi, A., Mikhailov, E., Pauliquevis, T., Petters, M. D., Prenni, A. J., Roldin, P., Rose, D., Schneider, J., Su, H., Zorn, S. R., Artaxo, P., and Andreae, M. O.: Rainforest Aerosols as Biogenic Nuclei of Clouds and Precipitation in the Amazon, Science, 329, 15131516, doi:10.1126/science.1191056, 2010.

Praglowski, J.: Effects of pre-treatment and embedding media on shape of pollen grains, Rev. Palaeobot. Palyno., 10, 203-208, doi:10.1016/0034-6667(70)90003-5, 1970.

Prahl, A. K., Springstubbe, H., Grumbach, K., and Wiermann, R.: Studies on sporopollenin biosynthesis - the effect of inhibitor of carotenoid biosynthesis on sporopollenin accumulation, $\mathrm{Z}$. Naturforsch. C, 40, 621-626, 1985.

Prenni, A. J., Petters, M. D., Kreidenweis, S. M., Heald, C. L., Martin, S. T., Artaxo, P., Garland, R. M., Wollny, A. G., and Pöschl, U.: Relative roles of biogenic emissions and Saharan dust as ice nuclei in the Amazon basin, Nat. Geosci., 2, 401-404, doi:10.1038/ngeo517, 2009.

Prenni, A. J., Tobo, Y., Garcia, E., DeMott, P. J., Huffman, J. A., McCluskey, C. S., Kreidenweis, S. M., Prenni, J. E., Pöhlker, C., and Pöschl, U.: The impact of rain on ice nuclei populations at a forested site in Colorado, Geophys. Res. Lett., 40, 227-231, doi:10.1029/2012g1053953, 2013.

Pummer, B. G., Bauer, H., Bernardi, J., Bleicher, S., and Grothe, H.: Suspendable macromolecules are responsible for ice nucleation activity of birch and conifer pollen, Atmos. Chem. Phys., 12, 2541-2550, doi:10.5194/acp-12-2541-2012, 2012.

Ranzato, M., Taylor, P. E., House, J. M., Flagan, R. C., LeCun, Y., and Perona, P.: Automatic recognition of biological particles in microscopic images, Pattern Recogn. Lett., 28, 31-39, 2007.

Razmovski, V., O’Meara, T. J., Taylor, D. J. M., and Tovey, E. R.: A new method for simultaneous immunodetection and morphologic identification of individual sources of pollen allergens, J. Allergy Clin. Immun., 105, 725-731, doi:10.1067/mai.2000.105222, 2000.

Reid, C. E. and Gamble, J. L.: Aeroallergens, Allergic Disease, and Climate Change: Impacts and Adaptation, EcoHealth, 6, 458470, doi:10.1007/s10393-009-0261-x, 2009.

Reitsma, T.: Size modification of recent pollen grains under different treatments, Rev. Palaeobot. Palyno., 9, 175-202, doi:10.1016/0034-6667(69)90003-7, 1969.
Robinson, N. H., Allan, J. D., Huffman, J. A., Kaye, P. H., Foot, V. E., and Gallagher, M.: Cluster analysis of WIBS single-particle bioaerosol data, Atmos. Meas. Tech., 6, 337-347, doi:10.5194/amt-6-337-2013, 2013.

Ronneberger, O., Schultz, E., and Burkhardt, H.: Automated pollen recognition using 3-D volume images from fluorescence microscopy, Aerobiologia, 18, 107-115, doi:10.1023/a:1020623724584, 2002.

Roshchina, V. V.: Autofluorescence of plant secreting cells as a biosensor and bioindicator reaction, J. Fluoresc., 13, 403-420, 2003.

Roshchina, V. V.: Fluorescing world of plant secreting cells, Science Publishers, 2008.

Roshchina, V. V.: Vital Autofluorescence: Application to the Study of Plant Living Cells, Int. J. Spectrosc., 2012, 124672, doi:10.1155/2012/124672, 2012.

Roshchina, V. V., Melnikova, E. V., and Kovaleva, L. V.: Changes in fluorescence during development of the male gametophyte, Russ. J. Plant Physl.+, 44, 36-44, 1997.

Roshchina, V. V., Yashin, V. A., and Kononov, A. V.: Autofluorescence of developing plant vegetative microspores studied by confocal microscopy and microspectrofluorimetry, J. Fluoresc., 14, 745-750, 2004.

Roulston, T. H. and Cane, J. H.: Pollen nutritional content and digestibility for animals, Plant Syst. Evol., 222, 187-209, doi:10.1007/bf00984102, 2000.

Rozema, J., Broekman, R. A., Blokker, P., Meijkamp, B. B., de Bakker, N., van de Staaij, J., van Beem, A., Ariese, F., and Kars, S. M.: UV-B absorbance and UV-B absorbing compounds (paracoumaric acid) in pollen and sporopollenin: the perspective to track historic UV-B levels, J. Phototoch. Photobio. B, 62, 108117, doi:10.1016/s1011-1344(01)00155-5, 2001.

Saari, S. E., Putkiranta, M. J., and Keskinen, J.: Fluorescence spectroscopy of atmospherically relevant bacterial and fungal spores and potential interferences, Atmos. Environ., 71, 202-209, 2013.

Sato, S., Katoh, N., Iwai, S., and Hagimori, M.: Establishment of reliable methods of in vitro pollen germination and pollen preservation of Brassica rapa (syn. B-campestris), Euphytica, 103, 29 33, 1998.

Satterwhite, M. B.: Spectral Luminescence Of Plant Pollen, Geoscience and Remote Sensing Symposium, 1990. IGARSS '90. "Remote Sensing Science for the Nineties", 10th Annual International, 1990, 1945-1948.

Satterwhite, M. B.: Luminescence of some airborne plant materials, Advances in Laser Remote Sensing for Terrestrial and Oceanographic Applications, edited by: Narayanan, R. M., and Kalshoven, J. E., Spie - Int Soc Optical Engineering, Bellingham, 52-62 pp., 1997.

Scharring, S., Brandenburg, A., Breitfuss, G., Burkhardt, H., Dunkhorst, W., von Ehr, M., Fratz, M., Giel, D., Heimann, U., Koch W., Lödding, H., Müller, W., Ronneberger, O., Schultz, E., Sulz, G., and Wang, Q.: Online monitoring of airborne allergenic particles (OMNIBUSS), in: Biophotonics, edited by: Popp, J. and Strehle, M., WILEY-VCH, Weinheim, 31-87, 2006.

Scheifinger, H., Belmonte, J., Buters, J., Celenk, S., Damialis, A., Dechamp, C., García-Mozo, H., Gehrig, R., Grewling, L., Halley, J. M., Hogda, K.-A., Jäger, S., Karatzas, K., Karlsen, S.R., Koch, E., Pauling, A., Peel, R., Sikoparija, B., Smith, M., Galán-Soldevilla, C., Thibaudon, M., Vokou, D., and Weger, L. 
A.: Monitoring, Modelling and Forecasting of the Pollen Season, in: Allergenic Pollen, edited by: Sofiev, M. and Bergmann, K.-C., Springer Netherlands, 71-126, 2013.

Schulte, F., Maeder, J., Kroh, L. W., Panne, U., and Kneipp, J.: Characterization of Pollen Carotenoids with in situ and High-Performance Thin-Layer Chromatography Supported Resonant Raman Spectroscopy, Anal. Chem., 81, 8426-8433, doi:10.1021/ac901389p, 2009.

Scott, R. J.: Pollen exine - the sporopollenin enigma and the physics of pattern, Molecular and Cellular Aspects of Plant Reproduction, edited by: Scott, R. J. and Stead, A. D., 49-81, 1994.

Shiraiwa, M., Selzle, K., Yang, H., Sosedova, Y., Ammann, M., and Pöschl, U.: Multiphase Chemical Kinetics of the Nitration of Aerosolized Protein by Ozone and Nitrogen Dioxide, Envir. Sci. Tech., 46, 6672-6680, doi:10.1021/es300871b, 2012.

Siljamo, P., Sofiev, M., Severova, E., Ranta, H., Kukkonen, J., Polevova, S., Kubin, E., and Minin, A.: Sources, impact and exchange of early-spring birch pollen in the Moscow region and Finland, Aerobiologia, 24, 211-230, doi:10.1007/s10453-0089100-8, 2008.

Sivaprakasam, V., Huston, A. L., Scotto, C., and Eversole, J. D.: Multiple UV wavelength excitation and fluorescence of bioaerosols, Opt. Express, 12, 4457-4466, 2004.

Sivaprakasam, V., Pletcher, T., Tucker, J. E., Huston, A. L., McGinn, J., Keller, D., and Eversole, J. D.: Classification and selective collection of individual aerosol particles using laser-induced fluorescence, Appl. Optics, 48, B126-B136, 2009.

Skjøth, C. A., Ørby, P. V., Becker, T., Geels, C., Schlünssen, V., Sigsgaard, T., Bønløkke, J. H., Sommer, J., Søgaard, P., and Hertel, O.: Identifying urban sources as cause of elevated grass pollen concentrations using GIS and remote sensing, Biogeosciences, 10, 541-554, doi:10.5194/bg-10-541-2013, 2013.

Sofiev, M., Siljamo, P., Ranta, H., and Rantio-Lehtimaki, A.: Towards numerical forecasting of long-range air transport of birch pollen: theoretical considerations and a feasibility study, Int. J. Biometeorol., 50, 392-402, doi:10.1007/s00484-006-0027-x, 2006.

Sofiev, M., Bousquet, J., Linkosalo, T., Ranta, H., RantioLehtimaki, A., Siljamo, P., Valovirta, E., and Damialis, A.: Pollen, Allergies and Adaptation, Biometeorology for Adaptation to Climate Variability and Change, edited by: Ebi, K. L., Burton, I., and McGregor, G. R., Springer, P.O. Box 17, $3300 \mathrm{Aa}$ Dordrecht, Netherlands, 75-106, 2009.

Sufra, S., Dellepiane, G., Masetti, G., and Zerbi, G.: Resonance Raman-spectrum of beta-carotene, J. Raman Spectrosc., 6, $267-$ 272, doi:10.1002/jrs.1250060602, 1977.

Taiz, L. and Zeiger, E.: Plant Physiology, Sinauer Associates, Incorporated, Sunderland, MA, USA, 2010.

Taylor, P. E., Jacobson, K. W., House, J. M., and Glovsky, M. M.: Links between pollen, atopy and the asthma epidemic, Int. Arch. Allergy Imm., 144, 162-170, doi:10.1159/000103230, 2007.

Tobo, Y., Prenni, A. J., DeMott, P. J., Huffman, J. A., McCluskey, C. S., Tian, G., Pöhlker, C., Pöschl, U., and Kreidenweis, S. M.: Biological aerosol particles as a key determinant of ice nuclei populations in a forest ecosystem, J. Geophys. Res., 118, 1010010110, doi:10.1002/jgrd.50801, 2013.

Toprak, E. and Schnaiter, M.: Fluorescent biological aerosol particles measured with the Waveband Integrated Bioaerosol Sensor WIBS-4: laboratory tests combined with a one year field study, Atmos. Chem. Phys., 13, 225-243, doi:10.5194/acp-13225-2013, 2013.

Traidl-Hoffmann, C., Kasche, A., Menzel, A., Jakob, T., Thiel, M., Ring, J., and Behrendt, H.: Impact of pollen on human health: More than allergen carriers?, Int. Arch. Allergy Imm., 131, 113, doi:10.1159/000070428, 2003.

Tylianakis, J. M., Didham, R. K., Bascompte, J., and Wardle, D. A.: Global change and species interactions in terrestrial ecosystems, Ecol. Lett., 11, 1351-1363, doi:10.1111/j.14610248.2008.01250.x, 2008.

van der Walt, I. D. and Littlejohn, G. M.: Storage and viability testing of Protea pollen, J. Am. Soc. Hortic. Sci., 121, 804-809, 1996.

von Blohn, N., Mitra, S. K., Diehl, K., and Borrmann, S.: The ice nucleating ability of pollen: Part III: New laboratory studies in immersion and contact freezing modes including more pollen types, Atmos. Res., 78, 182-189, doi:10.1016/j.atmosres.2005.03.008, 2005.

Wang, Q., Nakamura, S., Lu, S., Xiu, G., Nakajima, D., Suzuki, M., Sakamoto, K., and Miwa, M.: Release behavior of small sized daughter allergens from Cryptomeria japonica pollen grains during urban rainfall event, Aerobiologia, 28, 71-81, doi:10.1007/s10453-011-9212-4, 2012.

Welschmeyer, N. A.: Fluorometric analysis of chlorophyll $a$ in the presence of chlorophyll $b$ and pheopigments, Limnol. Oceanogr., 39, 1985-1992, 1994.

Wiermann, R. and Vieth, K.: Outer pollen wall, an important accumulation site for flavonoids, Protoplasma, 118, 230-233, 1983.

Willemse, M. T.: Changes in autofluorescence of pollen wall during microsporogenesis and chemical treatments, Acta Bot. Neerl., 21, 1-16, 1972.

Wilson, A. F., Novey, H. S., Berke, R. A., and Surprenant, E. L.: Deposition of inhaled pollen and pollen extract in human airways, New Engl. J. Med., 288, 1056-1058, doi:10.1056/nejm197305172882006, 1973.

Wlodarski, M., Kaliszewski, M., Kwasny, M., Kopczynski, K., Zawadzki, Z., Mierczyk, Z., Mlynczak, J., Trafny, E., and Szpakowska, M.: Fluorescence excitation-emission matrices of selected biological materials, in: Optically Based Biological and Chemical Detection for Defence III, edited by: Carrano, J. C., and Zukauskas, A., P. Soc. Photo-Opt. Inst., Spie-Int Soc Optical Engineering, Bellingham, U18-U29, 2006.

Wu, C. H. and Warren, H. L.: Natural autofluorescence in fungi, and its correlation with viability, Mycologia, 76, 1049-1058, 1984a.

Wu, C. H. and Warren, H. L.: Induced autofluorescence in fungi and its correlation with viability - Potential applications of fluorescence microscopy, Phytopathology, 74, 1353-1358, 1984b.

Yeloff, D. and Hunt, C.: Fluorescence microscopy of pollen and spores: a tool for investigating environmental change, Rev. Palaeobot. Palyno., 133, 203-219, doi:10.1016/j.revpalbo.2004.10.002, 2005.

Zhang, Y., Isukapalli, S. S., Bielory, L., and Georgopoulos, P. G.: Bayesian analysis of climate change effects on observed and projected airborne levels of birch pollen, Atmos. Environ., 68, 6473, 2013. 